Florida International University FIU Digital Commons

$10-24-2013$

\title{
Materials and Techniques in D'improvviso da immobile s'illumina, for Bass Clarinet, Two Orchestras, Piano and Percussion
}

Federico Bonacossa

Florida International University, federicobonacossa@yahoo.com

DOI: $10.25148 /$ etd.FI13120422

Follow this and additional works at: https://digitalcommons.fiu.edu/etd

Part of the Composition Commons

\section{Recommended Citation}

Bonacossa, Federico, "Materials and Techniques in D'improvviso da immobile s'illumina, for Bass Clarinet, Two Orchestras, Piano and Percussion" (2013). FIU Electronic Theses and Dissertations. 989.

https://digitalcommons.fiu.edu/etd/989 


\section{FLORIDA INTERNATIONAL UNIVERSITY}

Miami, Florida

\section{MATERIALS AND TECHNIQUES IN D'IMPROVVISO DA IMMOBILE S'ILLUMINA FOR BASS CLARINET, TWO ORCHESTRAS, PIANO AND PERCUSSION}

A thesis submitted in partial fulfillment of

the requirements for the degree of

MASTER OF MUSIC

by

Federico Bonacossa

2013 
To: Dean Brian Schriner

College of Architecture and the Arts

This thesis, written by Federico Bonacossa, and entitled Materials and Techniques in D'improvviso da immobile s'illumina, for Bass Clarinet, Two Orchestras, Piano and Percussion, having been approved in respect to style and intellectual content, is referred to you for judgment.

We have read this thesis and recommend that it be approved.

$\begin{array}{r}\hline \text { Jacob Sudol } \\ \hline \text { David Dolata } \\ \hline \text { Orlando Garcia, Major Professor }\end{array}$

Date of Defense: October 24, 2013

The thesis of Federico Bonacossa is approved.

Dean Brian Schriner College of Architecture and the Arts

Dean Lakshmi N. Reddi University Graduate School

Florida International University, 2013 
C Copyright 2013 by Federico Bonacossa

All rights reserved. 


\begin{abstract}
OF THE THESIS
MATERIALS AND TECHNIQUES IN D'IMPROVVISO DA IMMOBILE S'ILLUMINA FOR BASS CLARINET, TWO ORCHESTRAS, PIANO AND PERCUSSION
\end{abstract} by

Federico Bonacossa

Florida International University, 2013

Miami, Florida

Professor Orlando Garcia, Major Professor

D'improvviso da immobile s'illumina is a concerto for bass clarinet, two orchestras, piano, and percussion, that I composed during my graduate studies at Florida International University in Miami. The work is approximately 16 minutes long and is scored for 30 independent instrumental parts in addition to the bass clarinet soloist. Although the piece does not incorporate electronics, electronic music was a major influence in its creation, and the computer was used extensively as a compositional tool. In addition, the writings of Henry Cowell and the music of Sofia Gubaidulina influenced the concerto in a number of ways. While writing this work, I had to discover new ways to allow pure instinct to intermingle with strict calculation. This paper will discuss in detail the various techniques used in the creation of the concerto as well as some of the works that influenced it. 


\section{TABLE OF CONTENTS}

CHAPTER

PAGE

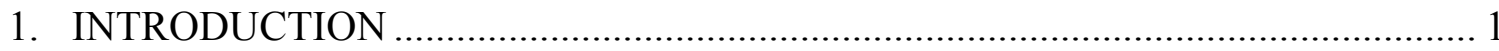

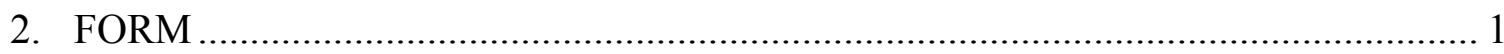

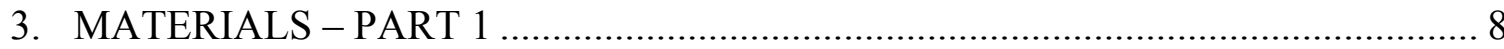

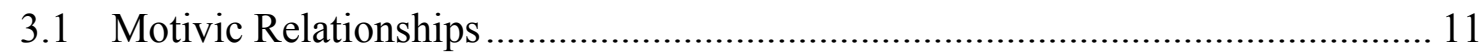

3.2 Metrically free sections and gestures........................................................ 14

3.3 Recurring Motives .................................................................................. 15

3.4 Additional motivic relationships.............................................................. 20

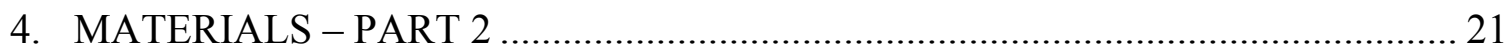

4.1 Frequencies to Durations: Henry Cowell's Rhythmicon.................................... 24

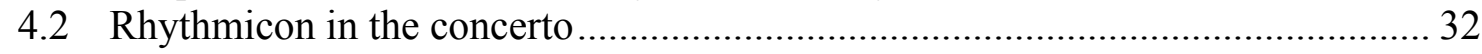

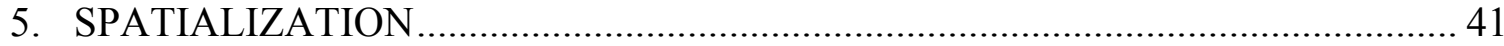

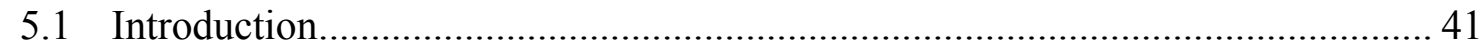

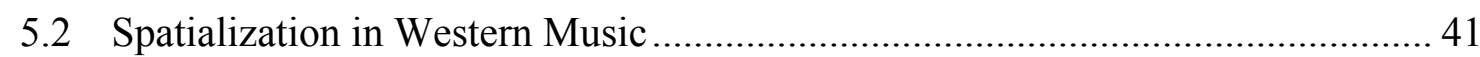

5.3 Spatialization in D'improvviso da immobile s'illumina ................................. 46

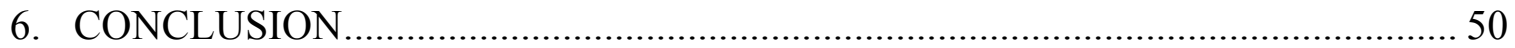

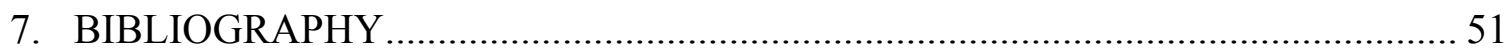

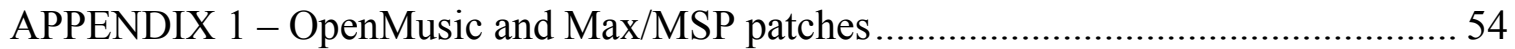

APPENDIX 2 - D'improvviso da immobile s'illumina - score (see additional file) 


\section{LIST OF FIGURES}

FIGURE

PAGE

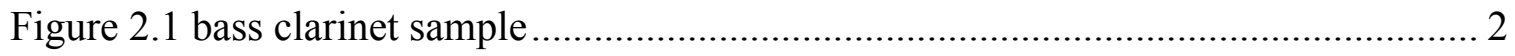

Figure 2.2 Formal outline ....................................................................................... 3

Figure 2.4 Excerpt from e poi, solo sfiorandole. ......................................................... 7

Figure 3.1 Spectral analysis of the bass clarinet sample used in the concerto................... 8

Figure 3.2 D’improvviso da Immobile S'illumina - bass clarinet introduction ................ 9

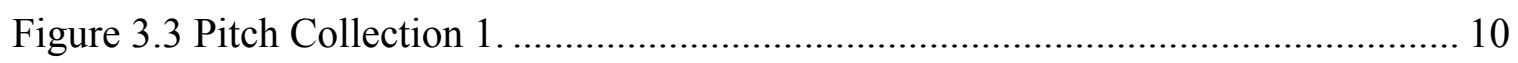

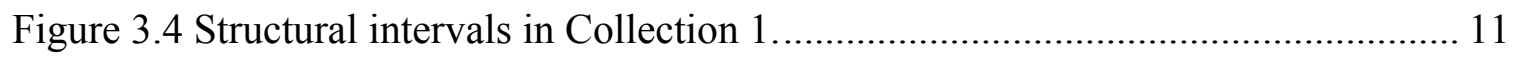

Figure 3.5 Excerpt from Solace for woodwing quintet................................................ 11

Figure 3.6 Formal outline used to compose e poi, solo sfiorandole ............................... 12

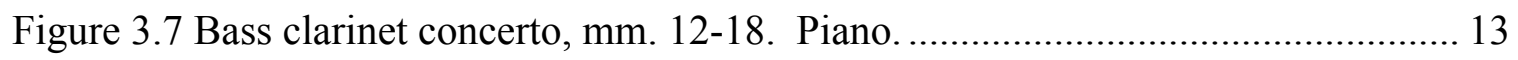

Figure 3.8 D'improvviso da immobile s'illumina, excerpt from m. 28. Bass clarinet..... 13

Figure 3.9 D’improvviso da immobile s'illumina, mm. 66-69. Bass clarinet................. 14

Figure 3.10 D'improvviso da immobile s'illumina mm. 67-69. Viola 2........................ 14

Figure 3.11 D'improvviso da immobile s'illumina, mm. 87. Double bass 2................. 15

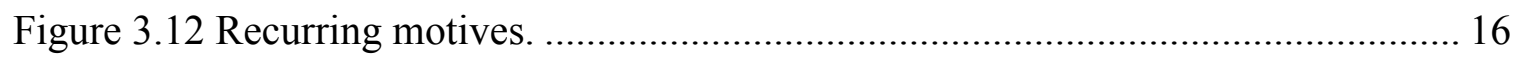

Figure 3.13 OpenMusic patch for expanding and compressing sets by multiplying

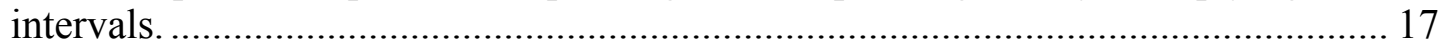

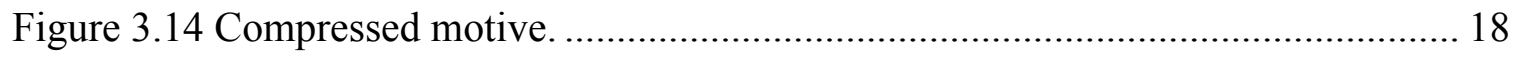

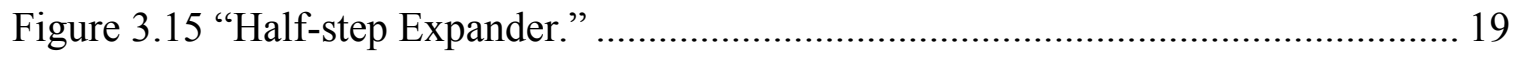

Figure 3.16 Motivic expansion. Concerto for Bass Clarinet, excerpt from m. 143. Bass

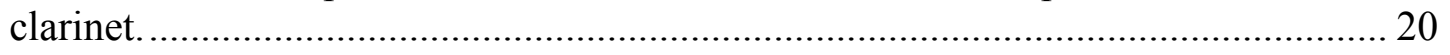

Figure 4.1 Spectral analysis of clarinet sample in Spear. ........................................ 22

Figure 4.2 OpenMusic patch used to filter spectral data. ......................................... 23 
Figure 4.3 Pitch collection derived from spectral data (Pitch Collection 2)................... 24

Figure 4.4 Rhythmic relationships based on the overtone series (Cowell 1958: 47). ...... 25

Figure 4.5 Note shapes proposed by Henry Cowell up the ninth note series. ................. 26

Figure 4.6 Durations derived from the ratio of the frequencies of an $\mathrm{A}^{4}$ and a justly tuned

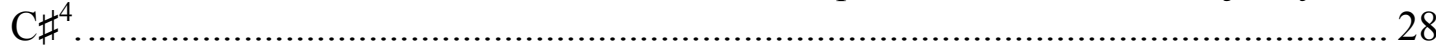

Figure 4.7 Sample page from James Tenney's Spectral CANON for CONLON

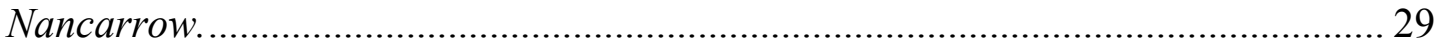

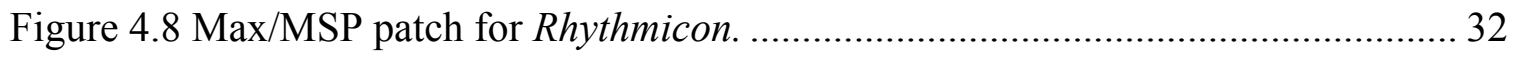

Figure 4.9 Abstraction used to assign durations to the frequencies in Collection 2........ 33

Figure 4.10 OpenMusic patch that assigns a duration to a midicent value based on its

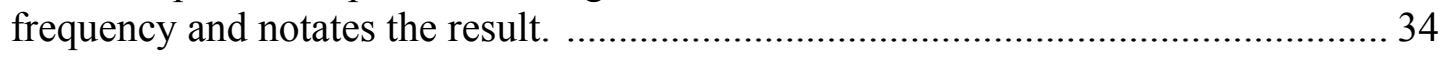

Figure 4.11 List of pitches and durations used in the rhythmicon sections. .................... 35

Figure 4.12 First measure of the raw score used to create the rhythmicon in d'improvviso

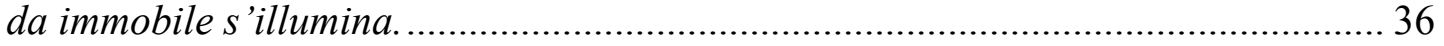

Figure 4.13 Approximation problems with the voice object in OpenMusic.................... 37

Figure 4.14 D'immprovviso da immobile s'illumina mm. 91-94. Clarinet 1.................. 38

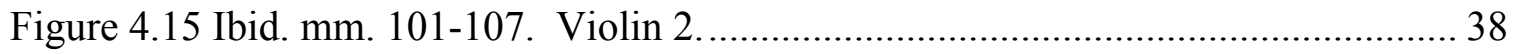

Figure 4.16 Pitches use in the rhythmicon section in order...................................... 39

Figure 5.1 Spherical Concert Hall, built for the 1970 German pavilion at the Osaka World Fair. Photo (C) Karlheinz Stockhausen ................................................................. 45

Figure 5.2 Seating chart for the D'improvviso da immobile s'illumina. ......................... 47

Figure 5.3 Cross fading in D'improvviso da immobile s 'illumina ................................. 48

Figure 5.4 D'improvviso da immobile s'illumina mm. 114-118................................... 49 


\section{INTRODUCTION}

D'improvviso da immobile s'illumina, explores the coexistence of two distinct sound worlds: one emerging from pure intuition representing the ability of our subconscious to naturally distill elements from the most diverse experiences, and a more "scientific" one, created by gathering data from a recorded sound with the help of a computer. The two approaches influenced one another: the computer was used to generate variations of the material created intuitively, and intuition guided a number of changes to the original spectral data. Electronic art music, was a major influence in this piece, and I attempted to adapt some of its idiomatic techniques to instrumental writing. But in the end, this, as all my other works, was another opportunity to explore the duality of our being that constantly presents a conflict between what we plan to do and what we feel is "right" (and vice-versa). The following chapters will discuss the form, materials, technique, and instrumentation of the piece in detail. D'improvviso da immobile s'illumina literally translates to "suddenly, while still, it illuminates." I chose to use a title in Italian, something I do not always do, partly because it is my native language, but most importantly because I found the sound of it to be more poetic than its English translation.

\section{FORM}

The form of the concerto is based on the shape of the waveform analysis of a short sound sample shown in Figure 2.1. 


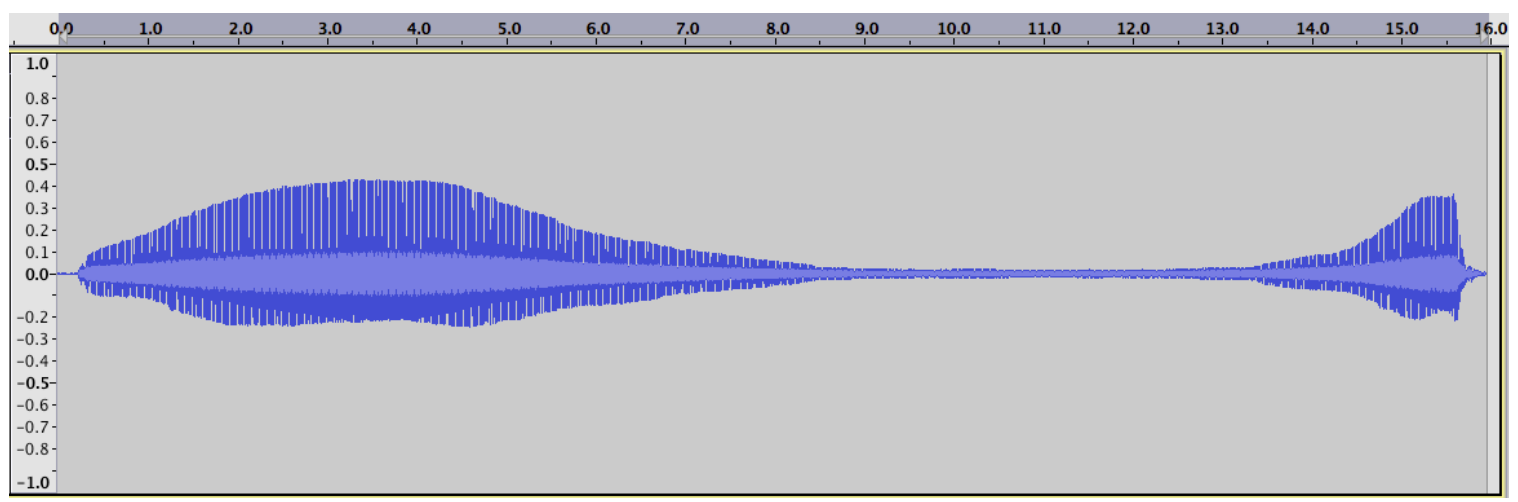

Figure 2.1 bass clarinet sample $(\mathrm{X}$ axis $=$ timeline $\mathrm{Y}$ axis $=$ amplitude $)$

This compositional approach is known as "spectral" and was pioneered in the early 70s by French composers Gérard Grisey and Tristan Murail. The originality of spectral techniques lies in its musical material not being generated from a basic rhythmic or melodic cell that is manipulated; instead, "[spectral] practices respond to complex physical circumstances" and the materials used are based on or inspired by the observation of natural sound phenomena (Rose 1996: 8).

The sample I used for D'improvviso, da immobile, s'illumina is a recording of a low B $b$ played on bass clarinet that I recorded during a meeting with Michael Sanchez, an FIU music student. During the meeting I asked the clarinetist to play a low B $b$ at a relatively loud dynamic level and then to fade the sound to a pianissimo before doing a sudden crescendo at the end. In order to use the waveform as a formal diagram, I interpreted the timeline of the actual sample so that each second would correspond to approximately one minute in the piece. The amplitude of the waveform provided an outline for dynamic shape and consequently suggested a general plan for the use of instrumental forces. It also suggested a possible subdivision into five main sections 
based on the overall dynamic level (Figure 2.2):

1. Introduction - bass clarinet solo

2. Orchestral gradual crescendo

3. Bass clarinet cadenza

4. Short dialogue between bass clarinet, bassoons and cellos

5. Orchestral recapitulation

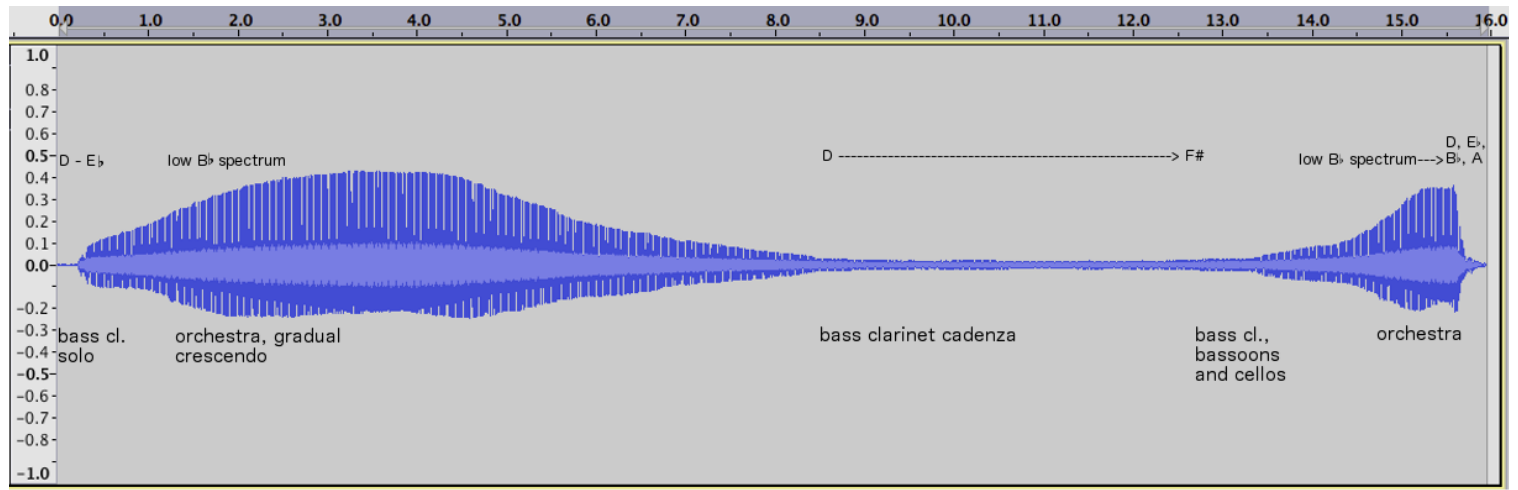

Figure 2.2 Formal outline

In addition to defining the main sections, I determined a general harmonic plan by identifying the central pitches or sonorities, which I would always dovetail into one another. The pitches indicated on top of the waveform in Figure 2.2 do not represent tonalities but rather a central pitch or pitches. Pitch centricity plays an important role in this piece as in all my compositions. Many post-tonal composers have been "deeply concerned with questions of centricity" (Kise 2011: 3) a topic to which I have given much thought. The pitch material used in the concerto will be discussed in detail in Chapters 3 and 4 . 
The sections indicated in the formal outline are clearly defined as far as the material is concerned, but the transition from one section to the other is usually very gradual. This gradual transformation of sonorities, commonly referred to as "interpolation," provides an effective way of infusing a sense of forward motion into otherwise static sonorities, enabling the music to travel between different harmonic fields and pitch centers. Interpolation in mathematics refers to the estimation of a value or values between two known values. In this case the values represent pitches, but they can represent other parameters as well.

I have previously used interpolation between sonorities in the work Tragos for double bass and live electronics, and in e poi, solo sfiorandole, for guitar and live electronics. In the piece falling, still for laptop, however, I created a computer program that interpolates between different presets. Each preset consists of a probabilistic table that gives the computer a list of sound samples to choose from, each with a specific weight, without determining the exact order. This effectively generates a structured computer improvisation. In both Tragos, and e poi, solo sfiorandole, the interpolations were first calculated using the OpenMusic patch shown in Figure 2.3. 


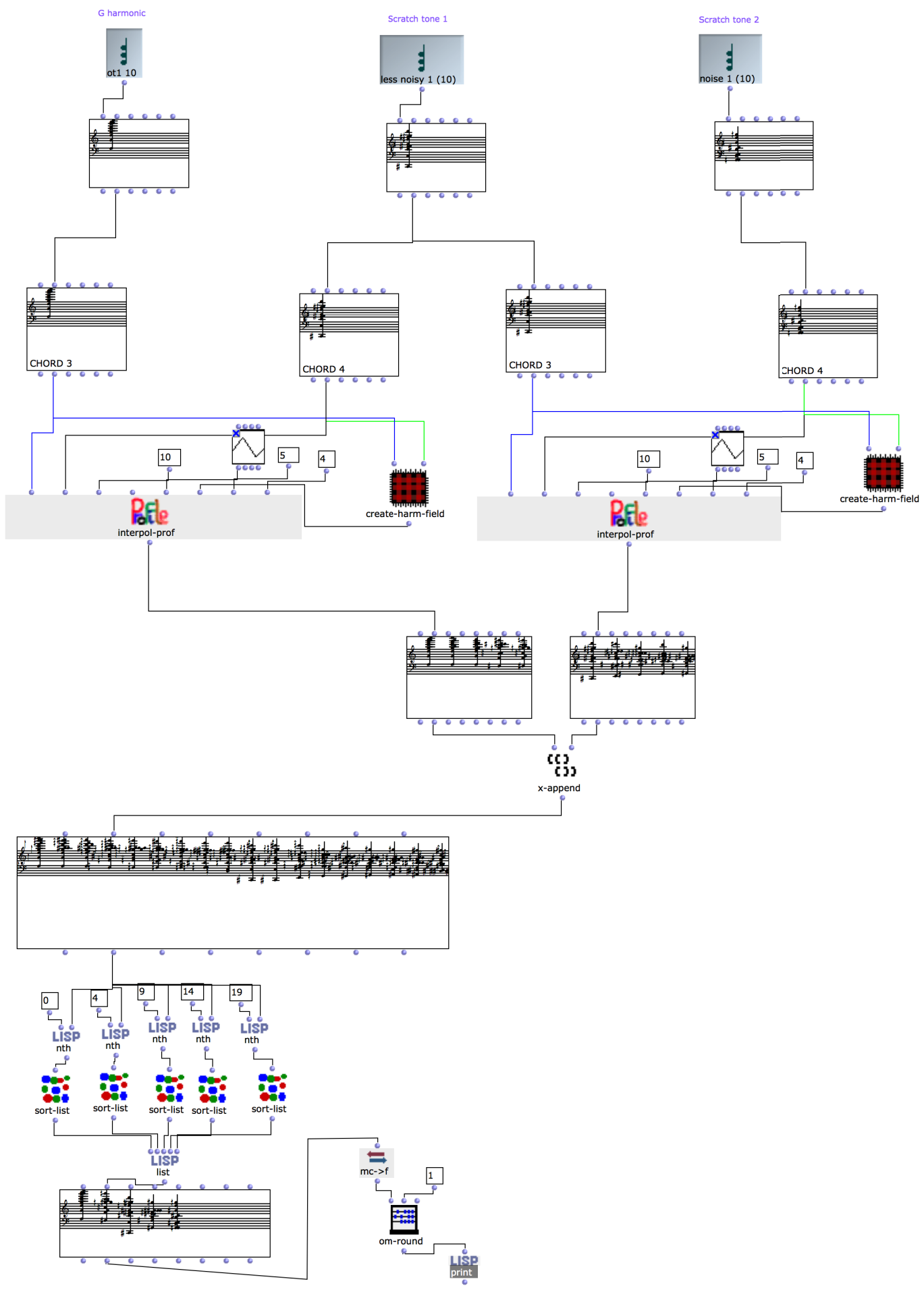

Figure 2.3 Interpolation patch. The content of the subpatch. See Appendix 1 for further details. 
OpenMusic is a visual programming language based on CommonLisp that was developed at the Institut de Recherche et Coordination Acoustique/Musique (IRCAM) in Paris. Although it may be used as a general-purpose programming environment, it was developed primarily as a tool for music composition. ${ }^{1}$

The patch shown in Figure 2.3 enables the user to generate very large numbers of interpolations. This, in turn, provides a wide range of possibilities from which the composer can choose. Figure 2.4 shows an excerpt from e poi, solo sfiorandole for classical guitar and live electronics. This section features the interpolation of two sonorities over the course of several minutes. The starting point consists of a single pitch (labeled "interpolation begins" in Figure 2.4), while the arrival point consists of a fivenote chord (labeled "interpolation ends").

\footnotetext{
${ }^{1}$ OpenMusic is available as a free download from: http://repmus.ircam.fr/openmusic/home.
} 

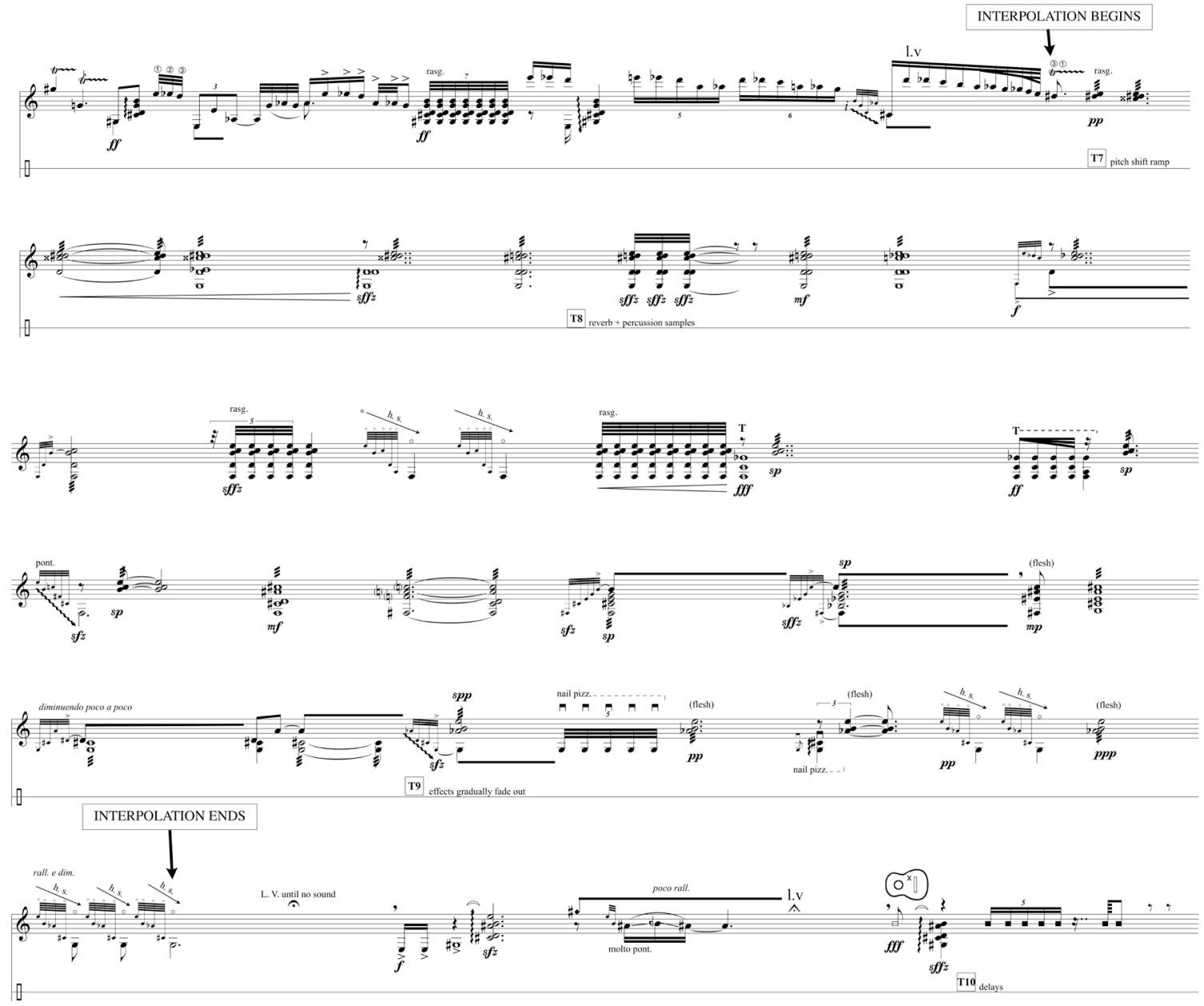

Figure 2.4 Excerpt from e poi, solo sfiorandole.

Similarly, interpolation in the concerto allows the music to gradually transform, the way that the waveform of the clarinet sample does; several distinct components can be isolated in the waveform, but they all are part of a single, coherent, sound. 


\section{MATERIALS - PART 1}

The concerto's pitch material can be reduced to two main pitch-collections. The first, discussed in this chapter, consists of various manipulations of a basic hexachord. The second, discussed in Chapter 4, was derived from the spectral analysis of the sound sample discussed in Chapter 2. For the sake of clarity, I will refer to the two pitchcollections as "collection 1" and "collection 2."

Collection 1 did not originate as a specific collection of pitches, but instead was derived from the pitches I used in the introduction. The introduction, in turn, was freely composed with only a few basic parameters in mind:

\section{1) Pitch centers}

I chose $\mathrm{D}$ and $\mathrm{E} b$ are the primary pitches, $\mathrm{D}$ as the initial central pitch because of its prominent role in the spectral analysis used for Collection 2 (shown in Figure 3.1). This provides a pivot point between the two collections.

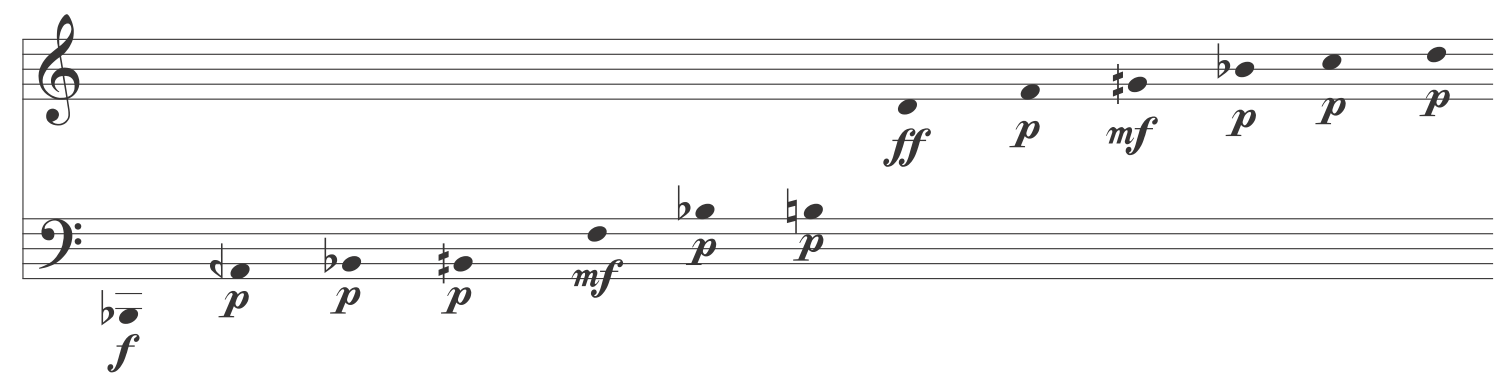

Figure 3.1 Spectral analysis of the bass clarinet sample used in the concerto (first 13 pitches only). Pitches are rounded to the nearest $1 / 4$ tone. 


\section{2) Germinal Motives}

I specifically composed the introduction so that it would include several distinctive motives that could be further elaborated later in the piece (Figure 3.2).

These include minor seconds (A), minor thirds (B), trills (C), octave leaps (D), and repeated notes $(\mathrm{E})$.
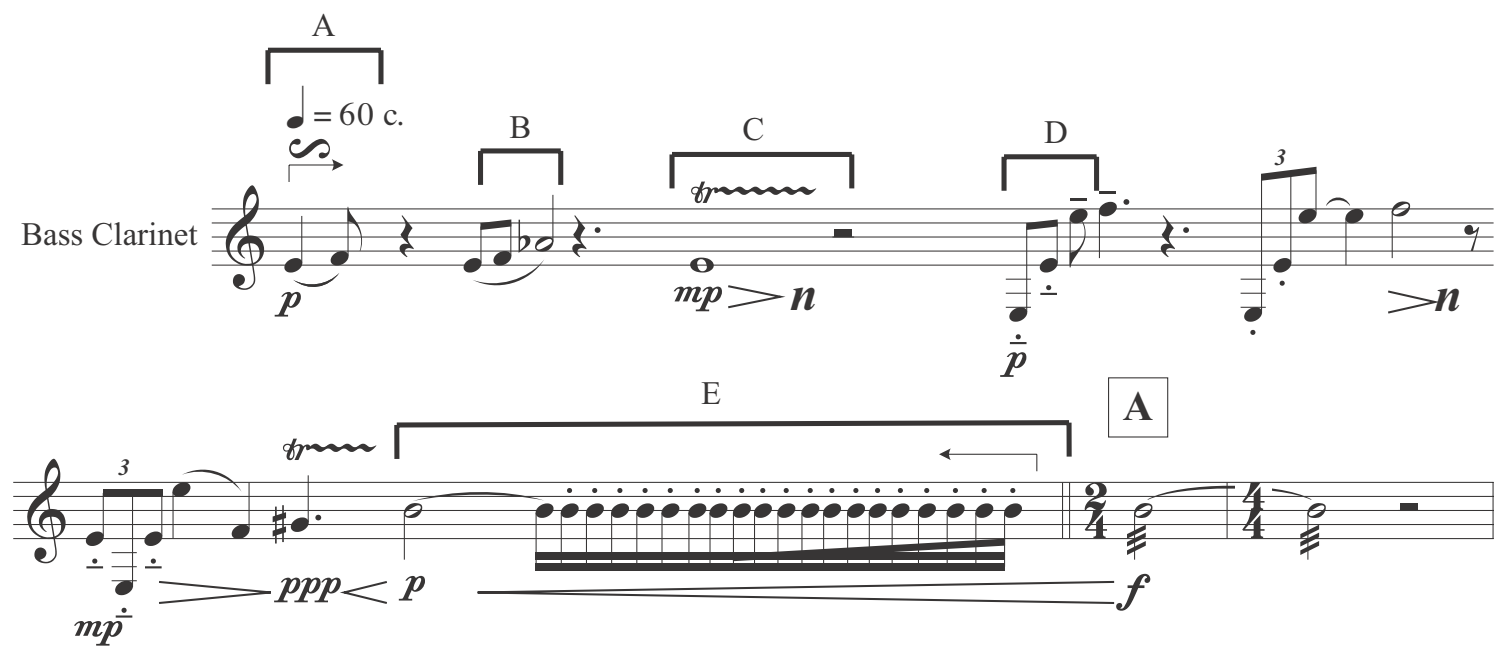

Figure 3.2 D'improvviso da Immobile S'illumina - bass clarinet introduction (transposed score).

The five pitches used in the introduction were then used to form the hexachord shown in

Figure 3.3 by adding an additional pitch (C) to fill in the gap between A and D. 


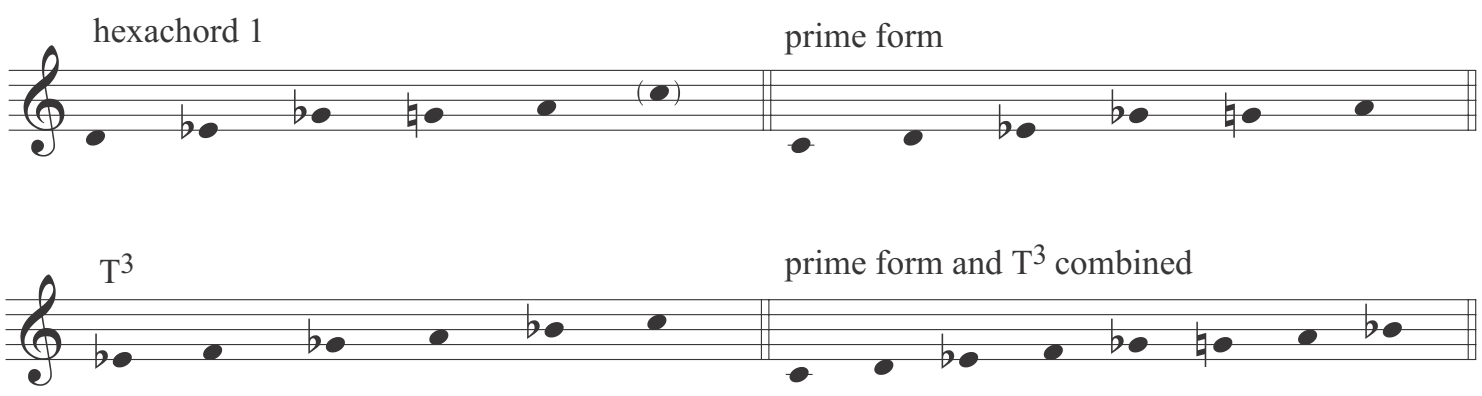

Figure 3.3 Pitch Collection 1.

When reduced to its prime form, this hexachord forms a symmetrical set (Forte name 6z29). Since this set is inversionally symmetrical, its inversion corresponds to a transposition of the original set $\left(\mathrm{T}^{3}\right)$. The inversion (or transposition) was combined with the prime form to produce a larger eight-note set that forms Collection 1. This set, and the harmonic spectra used in Collection 2, provided sufficient material for the remainder of the piece. I used OpenMusic to create patches that derive all note combinations and transpositions of the hexachords and octachord. This then served as a pool of material that I could draw from (see Figures 8.1.2 and 8.1.2.1 in Appendix 1).

The octachord in Collection 1 has several features that I find compelling and that, not coincidentally, characterize the pitch material of several of my earlier compositions. A few of the characteristics are:

1) It begins with a minor second that is typical of the Phrygian and Locrian modes.

2) The first and second notes of the set, $\mathrm{D}$ and $\mathrm{E} b$, have a corresponding note a perfect fifth above. The two pairs of fifths, especially when combined 
harmonically, provide an attractive blend of stability and tension and form the skeleton of the collection.

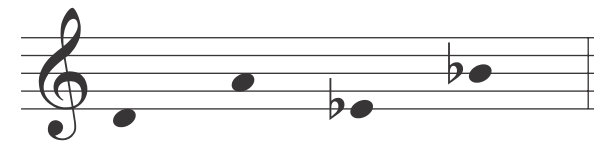

Figure 3.4 Structural intervals in Collection 1.

I used the same pitch collection in two of my previous compositions: Rivir for solo viola, and Solace for wind quintet. The excerpt shown in Figure 3.5 shows the opening measures of Solace. The entire passage uses only the four pitches shown in Figure 3.4.

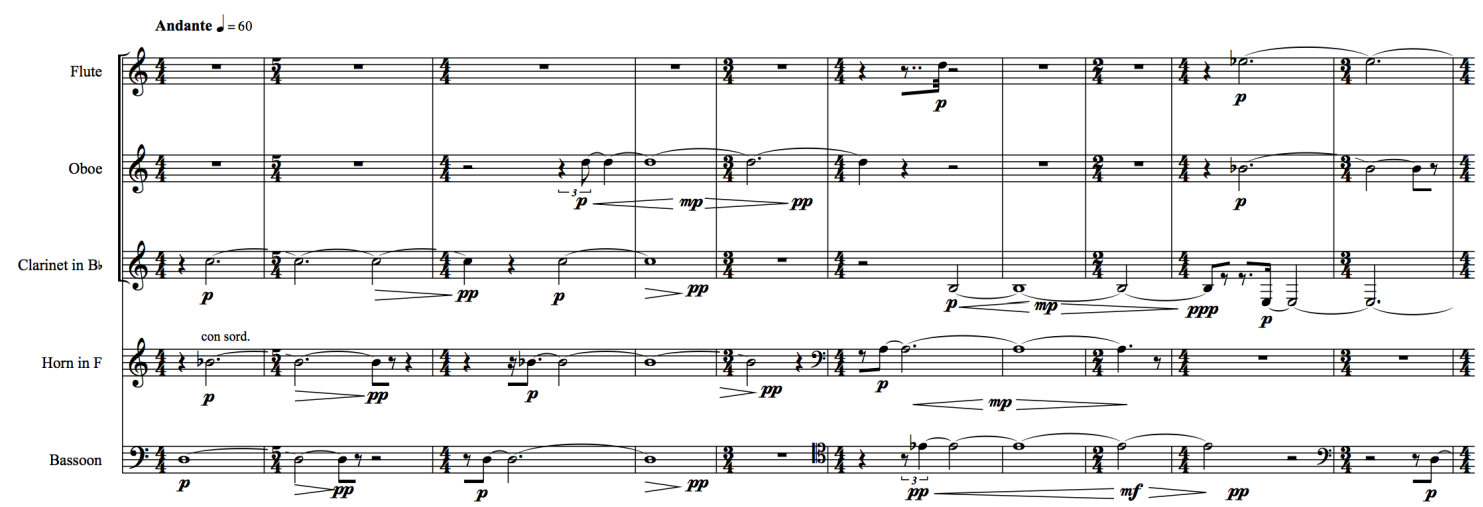

Figure 3.5 Excerpt from Solace for woodwing quintet (transposed score).

\subsection{Motivic Relationships}

Motivic coherence and elaboration is an important feature of my work. In Anoesis for solo piano, for instance, I created a formal scheme specifically designed to "force" motivic coherence. I used a similar model in e poi, solo sfiorandole (see scheme in Figure 3.6), and more recently in $R \sim T \sim L$ for classical guitar and reverb. 


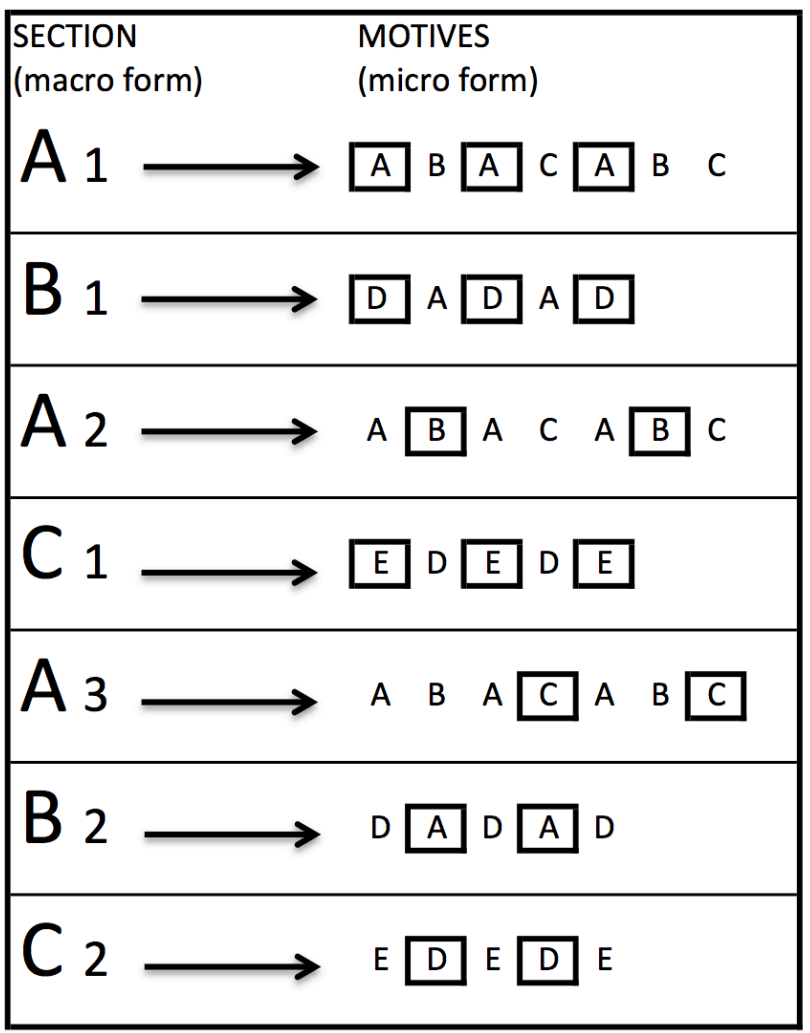

Figure 3.6 Formal outline used to compose e poi, solo sfiorandole.

In the diagram shown in Figure 3.6 the large letters represent large sections of the piece, while small letters represent short, distinctive sonic materials. The boxed letters indicate an emphasis on a particular motivic idea while non-boxed letters refer to material that has secondary importance. What makes this type of structure so useful is its flexibility; letters can indicate anything from a single interval to a timbre, noise, or even a rest. Although I had planned to use a similar model for the concerto, I abandoned the idea early on and chose instead to compose most sections intuitively, allowing the music to evolve naturally within the large-scale structure. The intuitive process was aided by a constant effort to create a sense of unity and direction and, as a result, it is not surprising 
that clear relationships between the different gestures were discovered a posteriori during analysis.

Motivic relationships are apparent throughout the piece. Page 8 of the score provides a good example (see Appendix 2): in measure 11, the pianist plays a four-note chromatic gesture shown in Figure 3.7. Three of the pitches, D, E b and F belong to the octachord from Collection 1, while the E natural, the central pitch of the gesture, does not. This introduces a slight variation to the basic set as well as a four-note chromatic cluster (the pedal is held down).

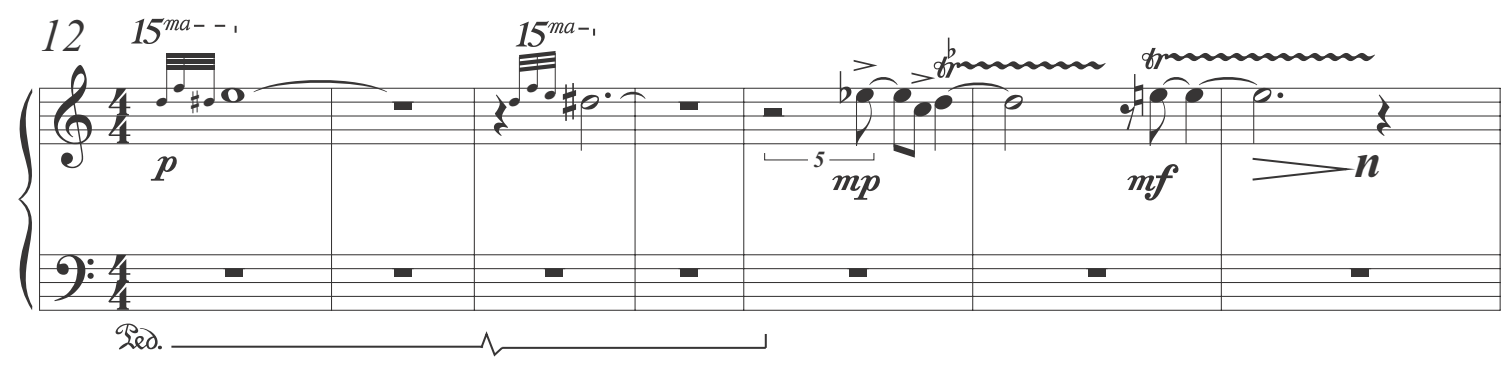

Figure 3.7 Bass clarinet concerto, mm. 12-18. Piano.

In the short cadenza in measure 28 , an expanded version of the same idea transposed a whole step below is heard on the bass clarinet (Figure 3.8).

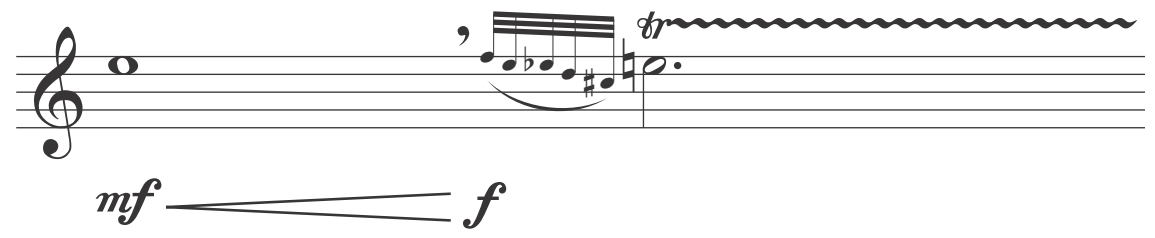

Figure 3.8 D'improvviso da immobile s'illumina, excerpt from m. 28. Bass clarinet (transposed score).

Later in the piece (see mm. 59-69 in Appendix 2), I used this five-note chromatic idea as 
a liberally repeated and rhythmically free gesture in the bass clarinet and cello 2 parts to contrast the steady pulse of the other instruments. In the same sections, the viola 1 and the double bass 1 play freely repeated gestures consisting of short bursts of repeated notes played jeté. This gesture is closely related to motive E from the introduction shown in Figure 3.2. Figure 3.9 shows another slight modification of the octachord in Collection 1.

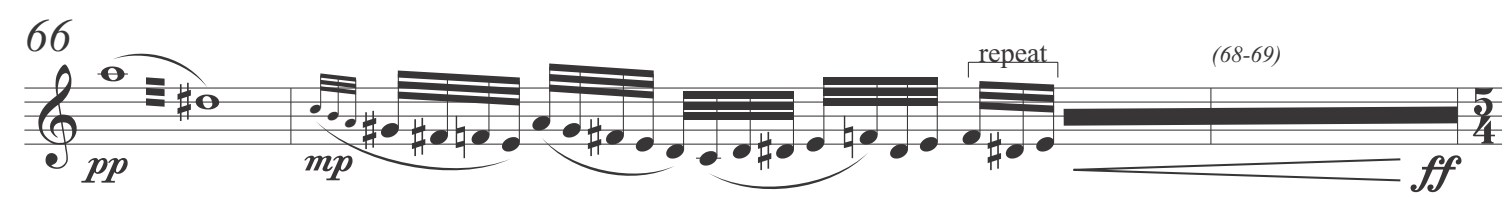

Figure 3.9 D'improvviso da immobile s'illumina, mm. 66-69. Bass clarinet (transposed score).

All pitches included in this passage are derived from Collection 1 with the exception of the $\mathrm{C} \#$. This "foreign" note however, immediately becomes part of the harmony thereby expanding the harmonic field. In fact it is simultaneously heard in the viola 2 part in a freely repeated pattern (Figure 3.10).

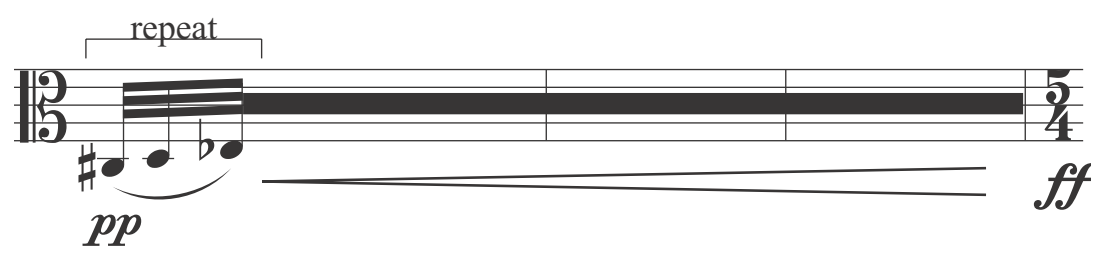

Figure 3.10 D'improvviso da immobile s'illumina mm. 67-69. Viola 2.

\subsection{Metrically free sections and gestures}

The concerto contains three non-metered (rhythmically improvised) cadenza-like sections in which the solo bass clarinet plays unaccompanied. In addition, several other metrically free gestures appear throughout the piece. In these parts, the rhythm is only 
approximated in the notation and the choice of the exact tempo and rhythmic proportions is left up to the performer. When this type of notation is used in combination with standard metric notation (as in mm. 59-69), the barlines are retained so as to provide a frame of reference for both the player and the conductor. I felt it necessary to include rhythmically free sections to balance the strictly repetitive rhythmic formulas associated with pitches from Collection 2, which also play an important role in the piece as will be seen in the next chapter.

Figures 3.10 and 3.11 show two examples of recurring metrically free gestures in the concerto: a chromatic pattern, and a glissando tremolo between two pitches. ${ }^{2}$

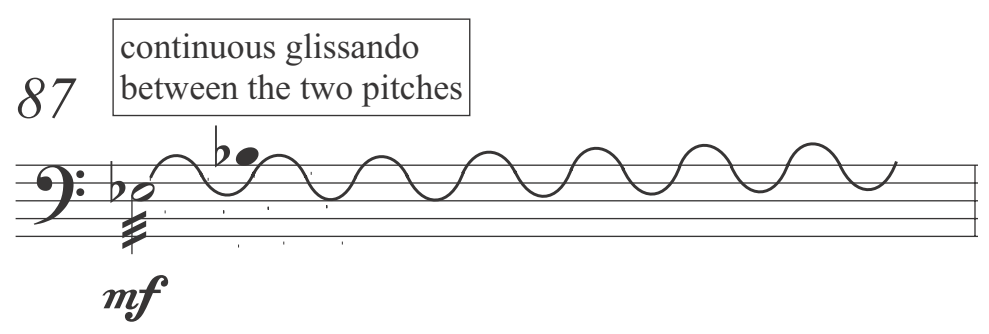

Figure 3.11 D'improvviso da immobile s'illumina, mm. 87. Double bass 2.

\subsection{Recurring Motives}

Figure 3.12 shows two additional recurring motives in the concerto. Collection 1 contains two instances of motive B (see Figure 3.2) a major third apart. This mirror tetrachord is a subset of the octatonic scale and is therefore not uncommon in $20^{\text {th }}$ and $21^{\text {st }}$-century music. It can be heard for example in John Chowning's electronic work

\footnotetext{
2 This type of gesture is common in the works of Sofia Gubaidulina. See for example: Sofia Gubaidulina, Hommage à T.S. Eliot: for soprano and octet, (Hamburg: H. Sikorski, 1991).
} 
a)

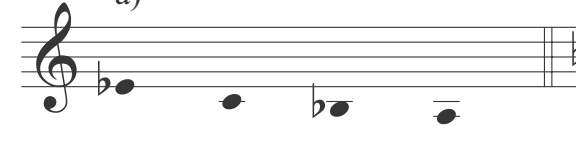

b)

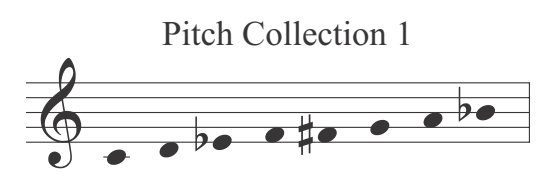

Figure 3.12 Recurring motives.

In my recent works, I have often experimented with the expansion and contraction of sets. For this purpose I created two simple patches in OpenMusic that enable me to experiment with many different transformations of a set. The two patches are based on two different approaches: expansion or contraction by multiplication, and expansion or contraction by addition or subtraction. The patch shown in Figure 3.13 is based on the first approach. It allows the user to simply multiply the intervals by a number, normally but necessarily an integer, and then see and hear the result. In this patch the user inputs a set in either midicents ${ }^{5}$ or using the chord-seq object editor (A). The intervals of the set are then abstracted using the $\mathrm{x}->\mathrm{dx}$ function, which calculates the distances between each note and the following. The intervals are then multiplied by an amount specified by the

\footnotetext{
${ }^{3}$ John Chowning, Turenas, Stria, Phoné, Sabelithe, 1993, Wergo Germany, B00008G1SW, Compact Disc.

${ }^{4}$ Sofia Gubaidulina, Concerto for Viola and Orchestra, (New York, NY: G. Schirmer, Inc. 2009, (C1997).

${ }^{5}$ Midicents in OpenMusic represent MIDI values. While normally in MIDI a middle $\mathrm{C}\left(\mathrm{C}^{4}\right)$ corresponds to the value $60, C \#^{4}$ corresponds to 61 etc., in midicents $C^{4}$ corresponds to $6000, C \#^{4}$ to 6100 and so on. The reason for this is to allow the representation of microintervals. For instance a value of 6050 corresponds to $\mathrm{a} \mathrm{C}^{4}$ a $1 / 4$ tone sharp. More information can be found in the OM User Manual available from: http://supportold.ircam.fr/forum-ol-doc/om/om6-manual/co/Score-Objects-Intro.html.
} 
user (B) and the result is then assigned a starting pitch, in this case $\mathrm{D}^{4}$, the same as the original set. A resulting set will be then derived that will have the same contour as the starting one. The multiplier can also be a non-integer, in which case the results usually need to be rounded depending on the type of tuning system being used. So for example, if the multiplier used is 0.5 the result will be the set shown in Figure 3.14.

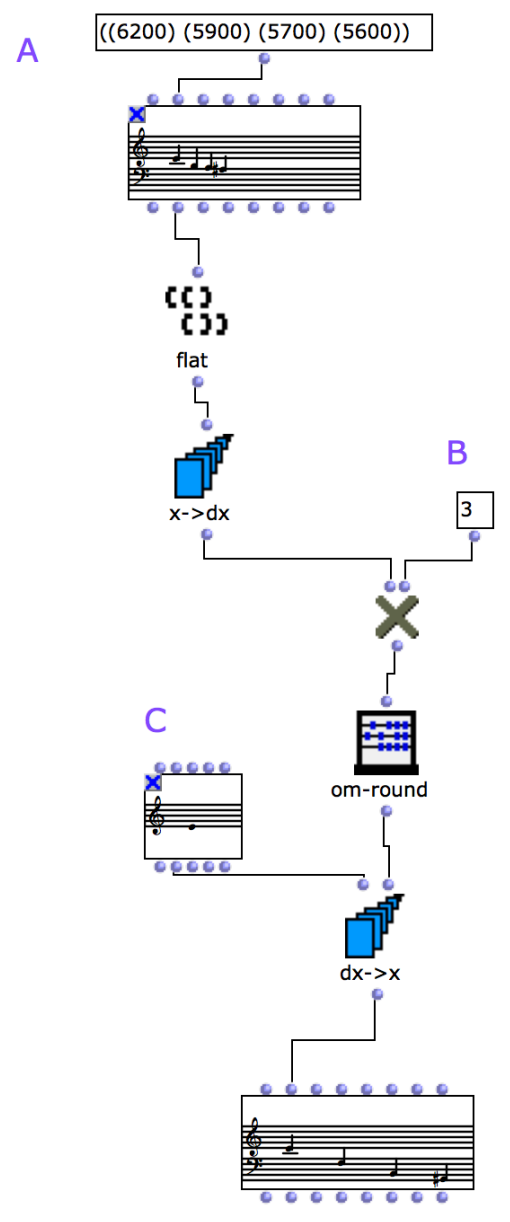

Figure 3.13 OpenMusic patch for expanding and compressing sets by multiplying intervals. 


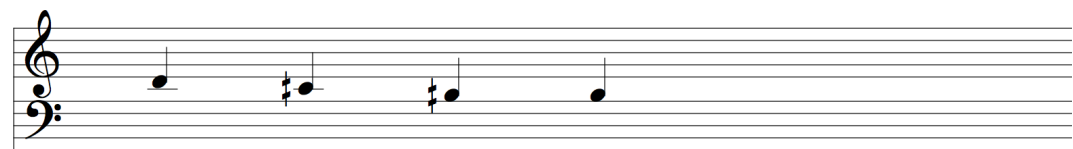

\begin{tabular}{|c|c|c|c|c|c|c|c|c|}
\hline t: $1315 \mathrm{~ms}$ & & & & & & & & Duration: $4000 \mathrm{~ms}$ \\
\hline midic $\quad \leqslant$ & Zoom & 100 & Staff & GF & $\div$ & Player & Microplayer $\mathrm{A}$ & $\ldots$ \\
\hline chord $\Rightarrow$ & Font size & $36 \div$ & Approx & $1 / 4$ & 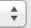 & & & \\
\hline
\end{tabular}

Figure 3.14 Compressed motive.

The patch shown in Figure 3.15 is based on the second approach. It calculates intervallic expansions by adding or subtracting a specified amount of half steps to each interval. The contents of the abstraction named "half-step-expander" are shown in Appendix 1 (Figure 8.1.4.1). 


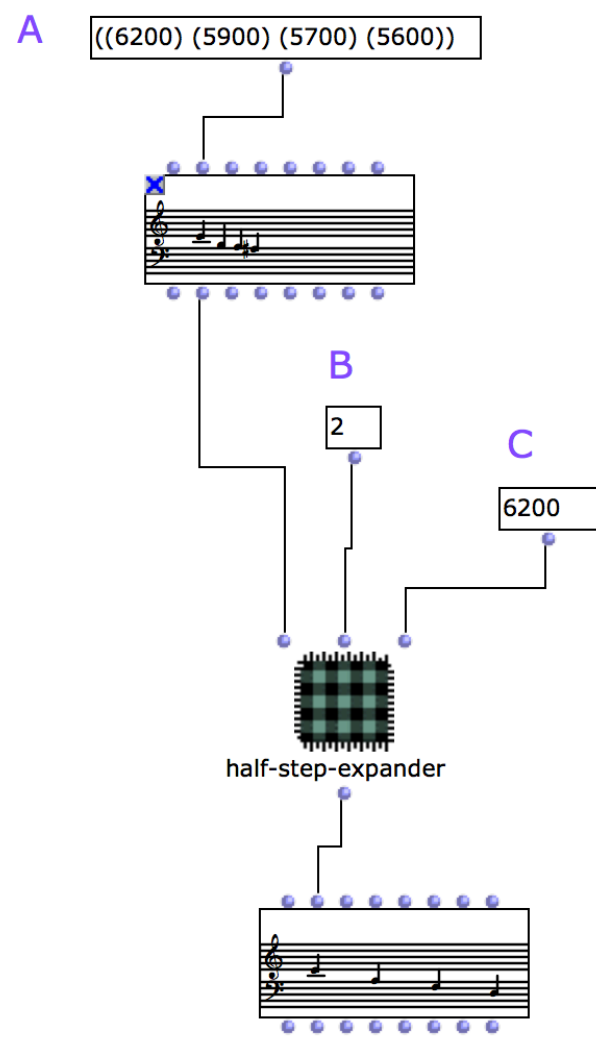

Figure 3.15 "Half-step Expander." A) Starting set, B) amount of half-steps to add to each interval, C) starting pitch of the resulting set.

Figure 3.16 shows an expansion of the "mirror tetrachord" used in the concerto, during the last bass clarinet cadenza. 


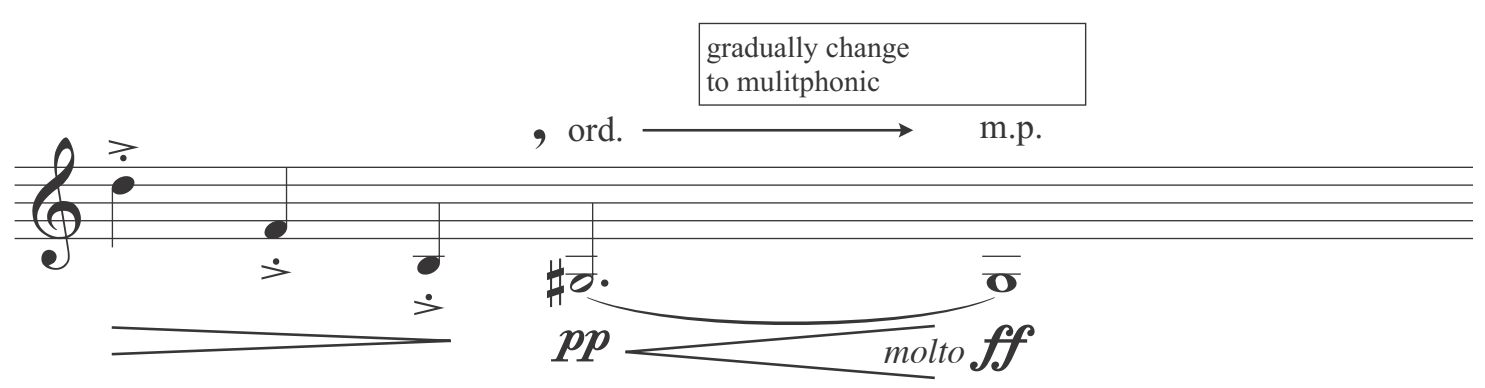

Figure 3.16 Motivic expansion. Concerto for Bass Clarinet, excerpt from m. 143. Bass clarinet (transposed score).

\subsection{Additional motivic relationships}

The mirror tetrachord shown in Figure 3.12 (motive b) becomes the basis for a 21measure section that begins on $\mathrm{m}$. 144. This section follows the long bass clarinet cadenza, which ends after establishing $\mathrm{F} \#$ as the pitch center. In this section, the bass clarinet dialogues with the two bassoons, joined by the cellos, each stand playing divisi. The mirror tetrachord appears throughout this section both horizontally and vertically. In measures 57-61, each cello plays the motive individually at a different rate, the motive becoming a vertical as well as a horizontal sonority. Each pair of cellos ends a half step apart (A-B b and F\#-G), creating a reference to the half step-relationship of the opening. 


\section{MATERIALS - PART 2}

As mentioned in Chapter 3, the second important pitch collection, which I will refer to as Collection 2, is based on a spectral analysis of the clarinet sample shown in Figure 2.1. The two collections represent contrasting approaches to musical material; the first, as we have seen, is based on various elaborations of recurring motivic ideas and a master set, while the second is based on information gathered from the analysis of a sound sample. Because of the extremely large amount of data contained in a sound of such length (16 seconds), I extracted a smaller sample, slightly longer than 200 milliseconds), from the loudest point of the sample, when the tone was very clear. I then used SPEAR ${ }^{6}$ (Figure 4.1) to analyze the sound and extract and derive information on the partials, their amplitude, and their duration. SPEAR is an application for audio analysis, editing and synthesis that essentially breaks down a sound into many individual sinusoidal tracks, each with varying frequency and amplitude. The information can then be easily manipulated and exported as an $\operatorname{SDIF}^{7}$ file containing detailed information on each partial.

\footnotetext{
${ }^{6}$ SPEAR is available as a free download from http://www.klingbeil.com/spear/.

${ }^{7}$ Sound Description Interchange Format.
} 


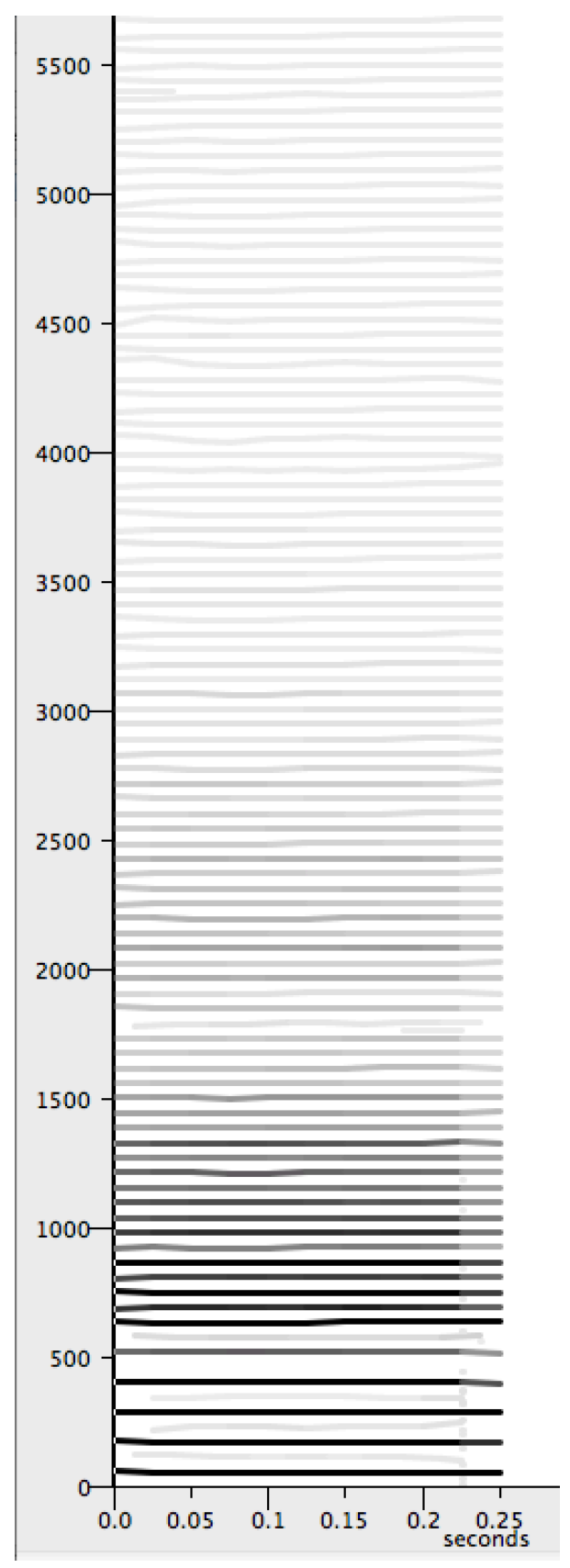

Figure 4.1 Spectral analysis of clarinet sample in Spear.

I then used OpenMusic to read the SDIF file and convert the information into standard notation. The object sdif->om in OpenMusic lets the user easily filter the data contained in the SDIF file by defining various parameters, such the minimum partial length, or the 
number and range of partials to show. For the purpose of the concerto, I envisioned an extremely large chord played by the whole orchestra. I did not want to use the data collected from the spectral analysis melodically as I felt that it would have a greater effect if all pitches were heard at the same time.

Figure 4.2 shows the OpenMusic patch I used to filter the data.

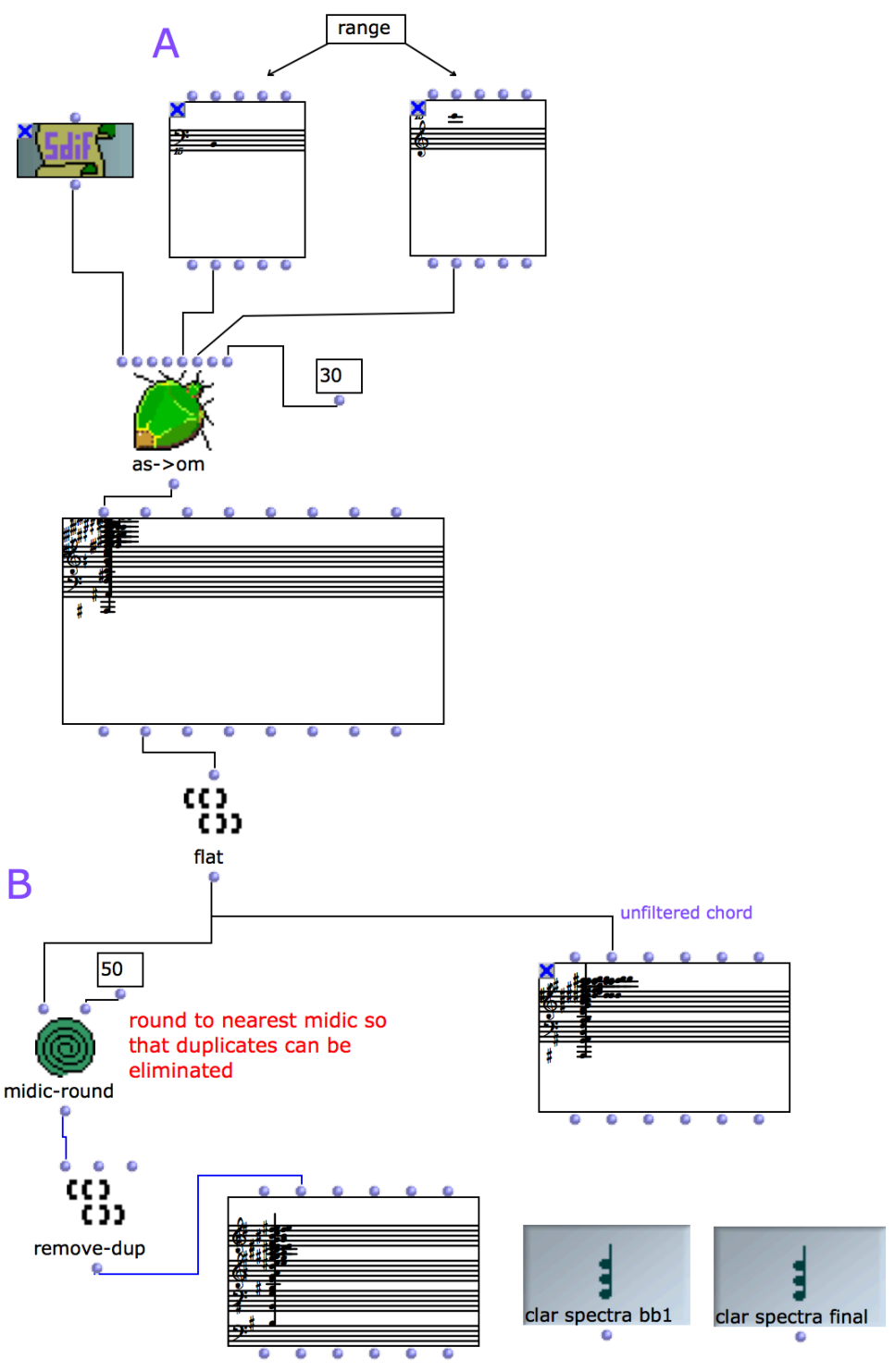

Figure 4.2 OpenMusic patch used to filter spectral data. 
Although this process can be done manually by reading the information directly from the SDIF file, OpenMusic provides a flexible way to experiment with different settings, and, most importantly, hear the results immediately. In other words, it allows the composer to make decisions based on the actual sound. In the patch shown, I specified the range based on the instruments I planned to use in the concerto (A). The frequency information in the SDIF file is converted by the om->sdif object to midicents values. Since most of the frequencies in the analysis are non-tempered pitches, I rounded the data to the nearest $1 / 4$ tone and then eliminated any duplicates in the resulting list. The sonority I ultimately used as my base material is a 38-note chord show in Figure 4.3.

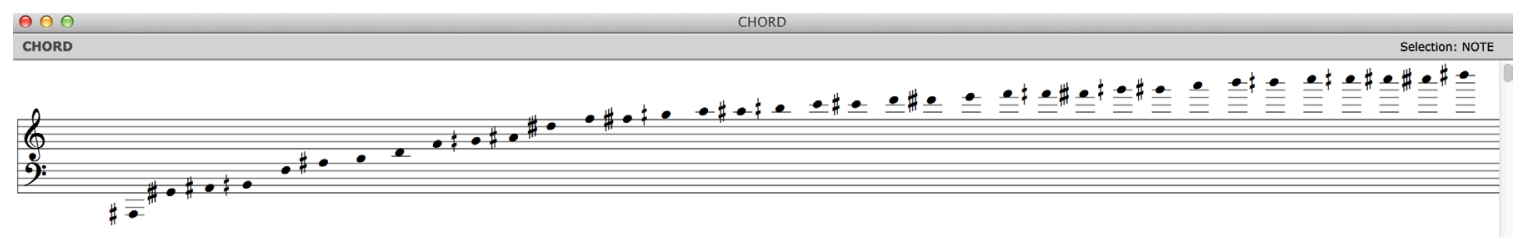

Figure 4.3 Pitch collection derived from spectral data (Collection 2).

\subsection{Frequencies to Durations: Henry Cowell's Rhythmicon}

In his book New Directions in Music, Henry Cowell lays out in detail his original approach to rhythm based on principles "already familiar in the field of harmony and counterpoint — that is, in the relation of tones to one another" (Cowell 1958: 46). He writes:

[...] a parallel can be drawn between the ratio of rhythmical beats and the ratio of musical tones by virtue of the common mathematical basis of both musical time and musical tone. The two times, in this view, might be said to be "in harmony," the simplest possible (Cowell 1958: 50-1).

Cowell proposes the application of the "principles of relating time to musical tone" not 
only to durations, but also to meter, dynamics, form, and tempo (Cowell 1958).

In the table shown in Figure 4.4, Cowell charts the rhythmic relationships inherent to a major triad that can be derived from the mathematical relationship between the fundamental and all the other tones. The first column indicates the tone's location in the harmonic series. Columns two and three indicate the interval of the tone in relationship to the fundamental and the name of the tones assuming $\mathrm{C}$ as the starting pitch. The last column shows the mathematical ratios of the vibrations using 16 as the fundamental frequency. Cowell uses the number 16 to simplify calculations even though it corresponds to a $\mathrm{C}^{0}$, a note barely audible by most humans.

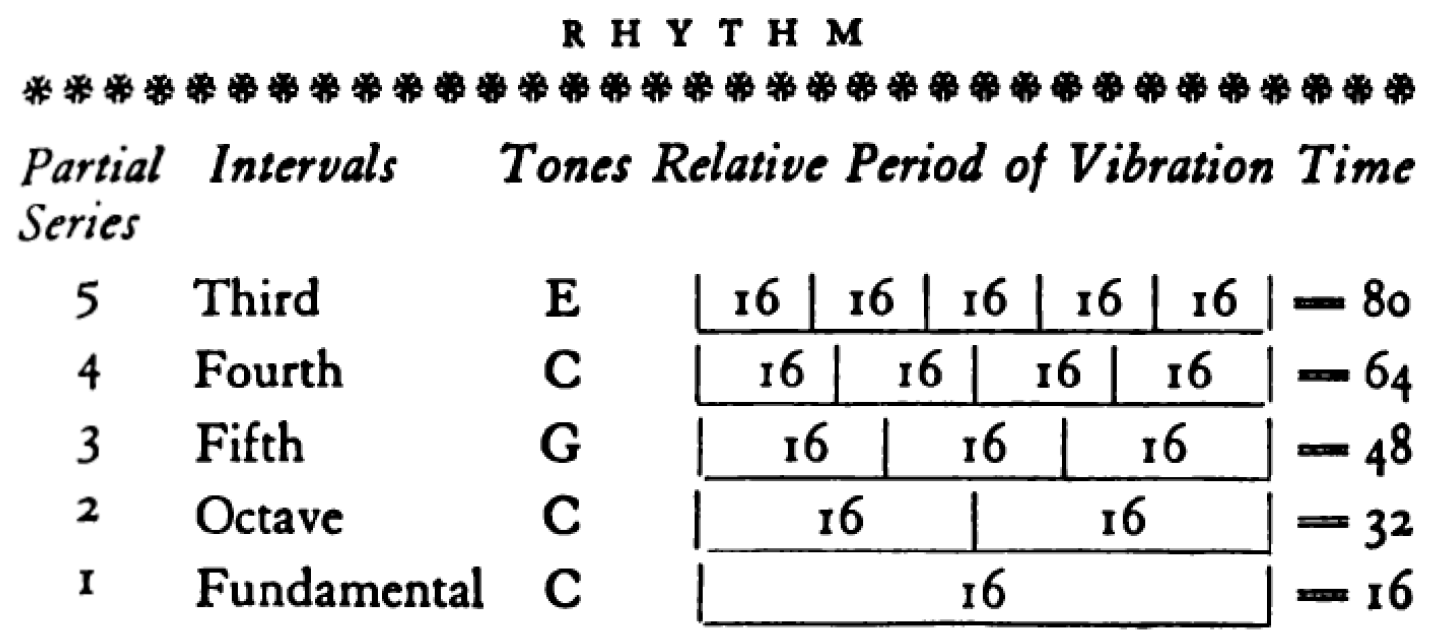

Figure 4.4 Rhythmic relationships based on the overtone series (Cowell 1958: 47).

Cowell stressed the similarities between "consonant" rhythmic relationships and consonant intervals, based on how many repetitions of a tone were needed before it would realign with the fundamental: "the smaller the number of units that must be passed over before that coincidence is re-established, the more consonant is the interval." Cowell also points out that the "the higher one goes in the overtone series, the greater the number 
of units that must be passed over, and the further is the effect from one of simple consonance." The reason why the tones result in harmony instead of a "chaos of sounds" he writes, "is that at regular intervals the vibrations coincide" (Cowell 1958: 47-48).

Cowell utilizes the ratios of the intervals in the harmonic series to create a "rhythmic harmony" so that, for example, a melody with a pulse of three half notes in the space of two would correspond to the interval of a pure perfect fifth, five quarters in the space of four to a pure major third and so on (Cowell 1958: 53). He also suggested extending the standard notational system by adding new shapes to represent note-values, based on what division of the whole note they represent. Figure 4.5 shows some of the note shapes suggested by Cowell (see Cowell 1958: 58).

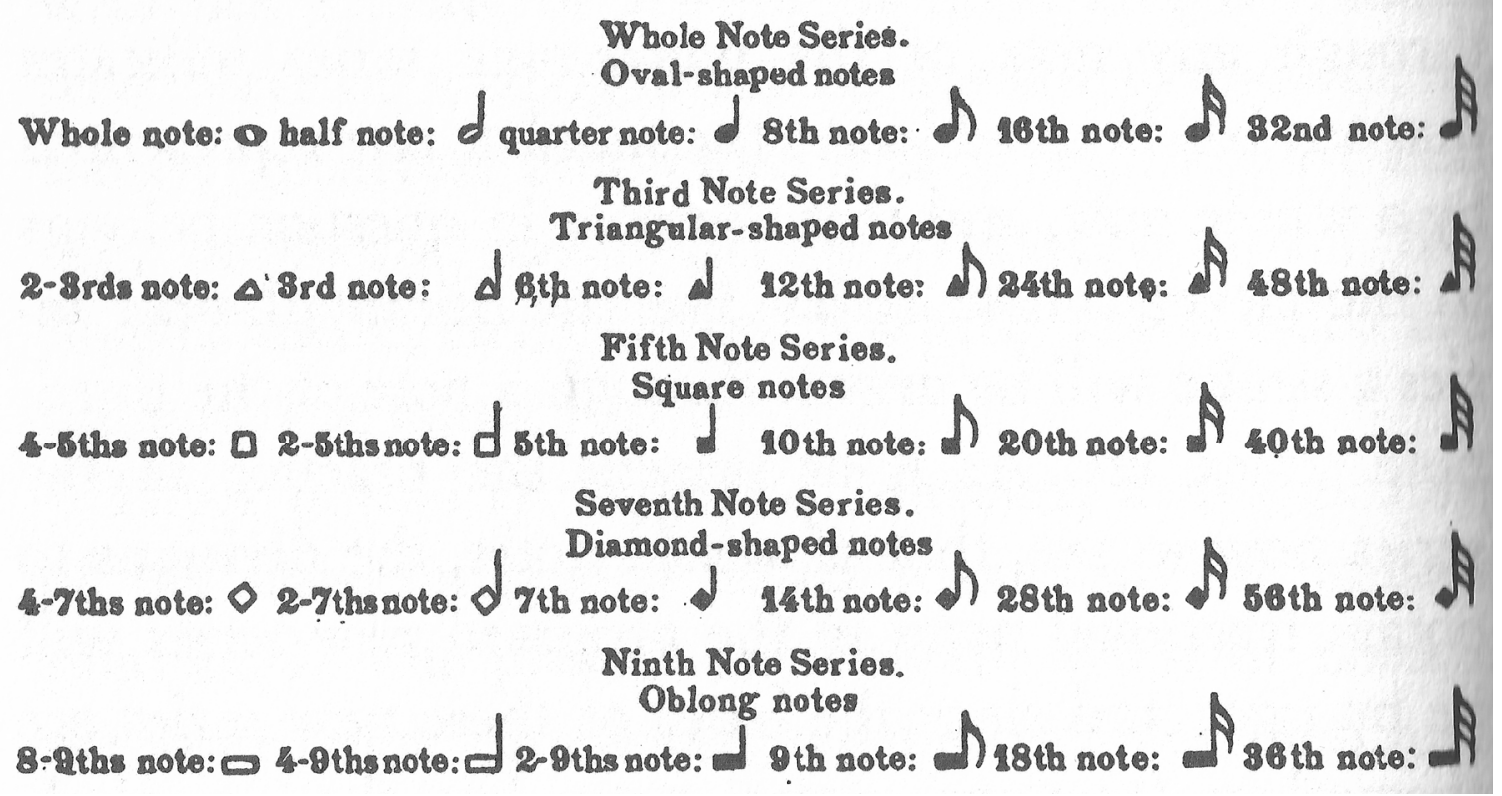

Figure 4.5 Note shapes proposed by Henry Cowell up the ninth note series.

He then gives various example of their use, many of them quite complex, admitting that 
most musicians would probably find them quite difficult to perform:

An argument against the development of more diversified rhythms might be their difficulty of performance. It is true that the average performer finds crossrhythms hard to play accurately; but how much time does the average performer spend in practicing them? Cross-rhythms are difficult and must be familiar before proficiency can be obtained in performing them; but if even a few minutes a day are seriously devoted to mastering them, surprising results are obtained. Surely they are as well worth learning as the scales, which students sometimes practice hours a day for years (Cowell 1958: 64).

He also makes the important point that complex rhythmic relationships can be easily performed by a player piano and even suggests the creation of an instrument that would assign specific rhythms to each pitch (Cowell 1958: 64).

Cowell's dream became reality through support by Charles Ives, who commissioned the Russian inventor Leon Theremin to build a rhythmicon, a machine that would convert pitch into rhythm and vice-versa. Theremin built two models in 1932, effectively creating the first rhythm machine, but neither was ever reliable enough to be used in performance (Baron and Buffington: 1932 Rhythmicon). In 1960 Theremin built another rhythmicon while at the Moscow Conservatory or possibly the USSR Sound Recording Institute. The instrument could perform complex polyrhythms such as 7 against 9 or 5 against 13. This model to this day is still in working condition ${ }^{8}$ (Baron and Buffington: 1960s Rhythmicon).

In New Musical Resources, Cowell always utilizes ratios based on the overtone series although he realized that they are in some cases significantly different from the ratios found in equal temperament. The reason for his choice is easy to understand if we assign durations to two pitches a major third apart using just intonation and equal

\footnotetext{
${ }^{8}$ For a video demonstration of the Rhythmicon see http://www.youtube.com/watch?v=HkodVcuPVAo.
} 
temperament and compare the results (see Figure 4.6). For instance, taking $\mathrm{A}^{4}$ as the fundamental, if we calculate the duration of $C \sharp^{5}$ based on its frequency in the tempered scale $(554.3653 \mathrm{hz})$ and relate it to the fundamental $(440 \mathrm{hz})$, we end up with a complex ratio even if we round the top frequency to $554 \mathrm{hz}$, in which case it would be 277/220. If, however, we use a justly tuned $C \sharp^{4}(550 \mathrm{hz})^{9}$, we obtain the much simpler ratio $5 / 4$. In terms of durations, this means that for every four repetitions of the fundamental there will be five repetitions of the third (see Figure 4.6).

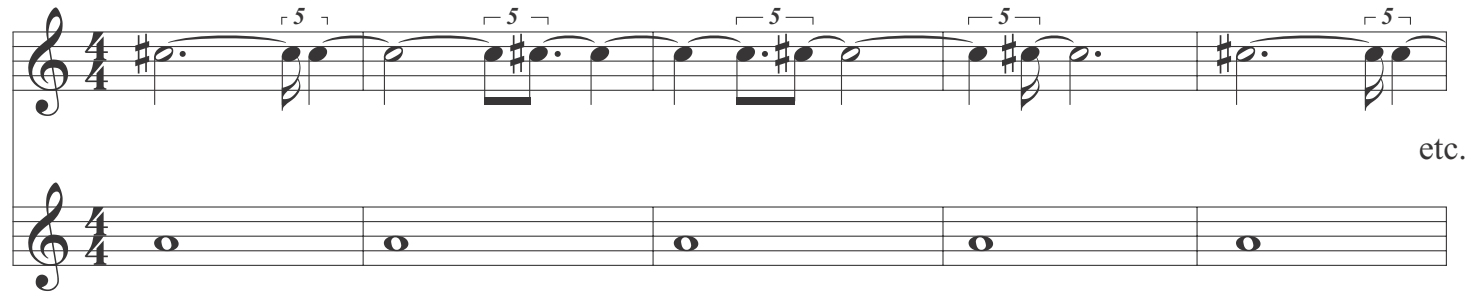

Figure 4.6 Durations derived from the ratio of the frequencies of an $\mathrm{A}^{4}$ and a justly tuned $\mathrm{C} \sharp^{4}$. The duration of the $\mathbf{C} \#$ may be though of as a large quintuplet spanning four bars.

James Tenney used the same process in several of his pieces, most notably in Spectral CANON for CONLON Nancarrow (Figure 4.7) in which, not coincidentally, he tunes the player piano so as to obtain the first 24 partials of the harmonic series (Polansky 1984: 1). ${ }^{10}$

\footnotetext{
${ }^{9}$ The fifth partial of $\mathrm{A}^{4}$ is $\mathrm{C}^{7}$ which has a frequency of $2200 \mathrm{~Hz}$. In this case we need to divide it by four to lower it two octaves.

${ }^{10}$ There are many other examples, especially by North American composers (see Wannamaker 2012) and even an "Online Rhythmicon" created by Nick Didkovsky.
} 


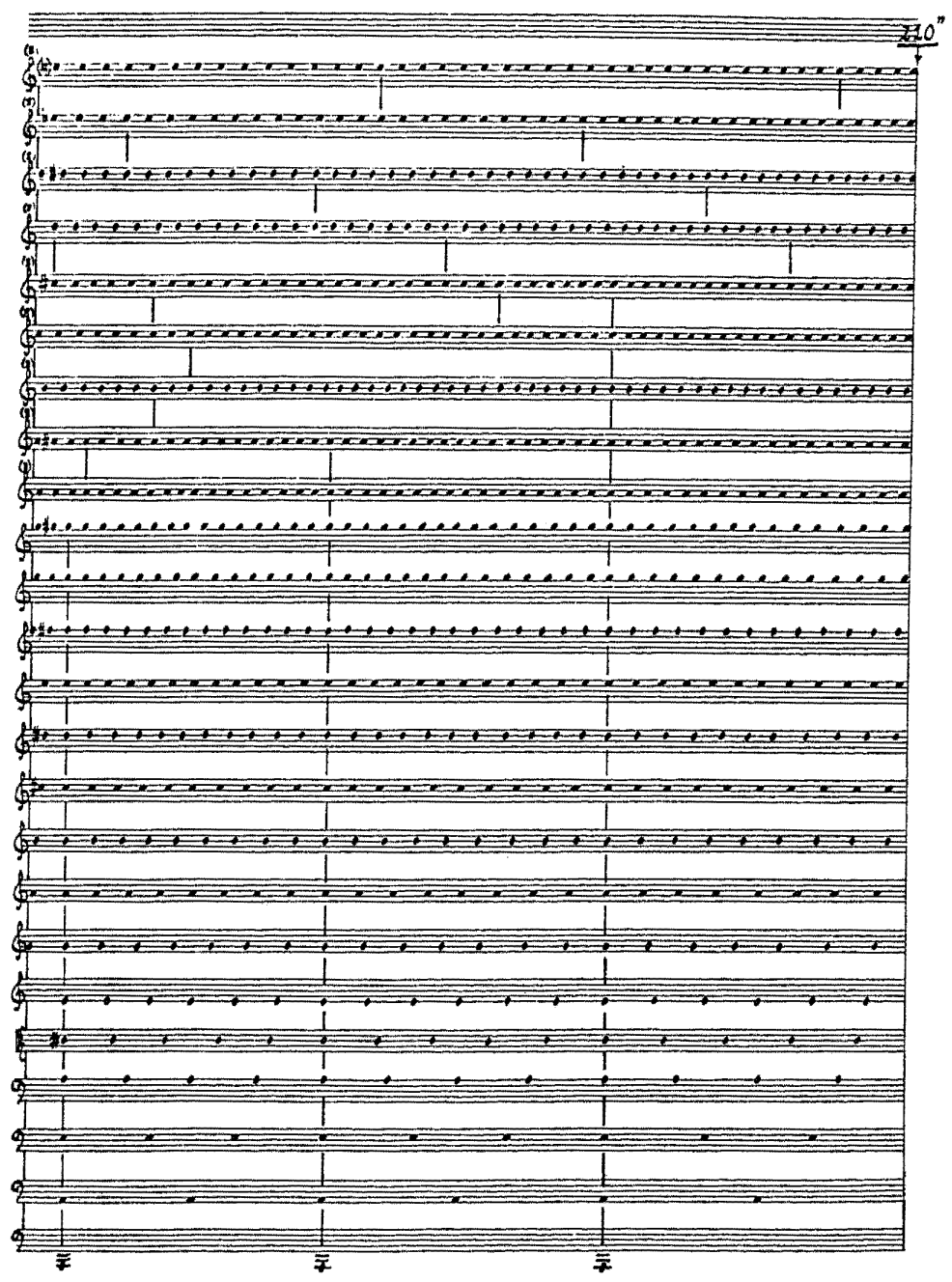

Figure 4.7 Sample page from James Tenney's Spectral CANON for CONLON Nancarrow.

The approach I used to calculate durations in the concerto is similar to Cowell's, but my system differs from his in that the frequencies have an absolute duration based on their rate of vibration and not just in relationship to one another. In addition, durations for each note were calculated after the frequencies were rounded; therefore they are based on the frequency actually being performed and not on their hypothetical place in the harmonic series. This system, however, created some complications when the durations 
were converted into rhythmic values because of the complex ratios they often generated. Therefore, in some cases, the durations had to be simplified to avoid making the notation exceedingly complicated.

I began working with the idea of relating pitch to durations, during my studies at FIU, before ever reading Henry Cowell's book, particularly while studying and writing electronic music. I first experimented with the idea while composing simple electronic pieces in which I looped the same sample simultaneously at different speeds. This simple technique creates a compelling sense of organization while at the same time, if enough layers are used, a complex and continuously changing texture, not unlike the sound produced by hundreds of birds singing at the same time. My interest in repetitive polyrhythms however, goes back several years to pieces such as Spindrift for guitar trio, in which all three guitars often play independent parts, periodically meeting at specific points. I continued to work using what I now simply call "rhythmicons" particularly in pieces that involved electronics, as the computer makes it easy to create perfectly consistent repetitions, no matter how complex the relationships between the parts. In addition, with the computer there are no limitations with respect to tuning, and the relationships between pitch and durations can be left intact.

In the opening of Tragos for double bass and live electronics I used Max/MSP to record a live sample of the bass into a buffer and then play the sample back at multiple different speeds simultaneously, thereby creating a harmonic series of the sample. In the sound installation Rhythmicon, written in 2012, I created a program that analyses frequency and amplitude data from either ambient sounds or a sound recording and then tunes to it by looping many layers, up to 50 in the example, of a single sound sample of a 
glass bowl to the frequencies it detects. The program, shown in Figure 4.8, determines the playback speed of the sample based on the relationship between the previously determined sample frequency and the frequency to which it is tuned. In addition to speed and amplitude, each sample is assigned a randomly generated panning value. The contents of the poly subpatch are shown in Figure 8.2.1.1 in Appendix 1. 


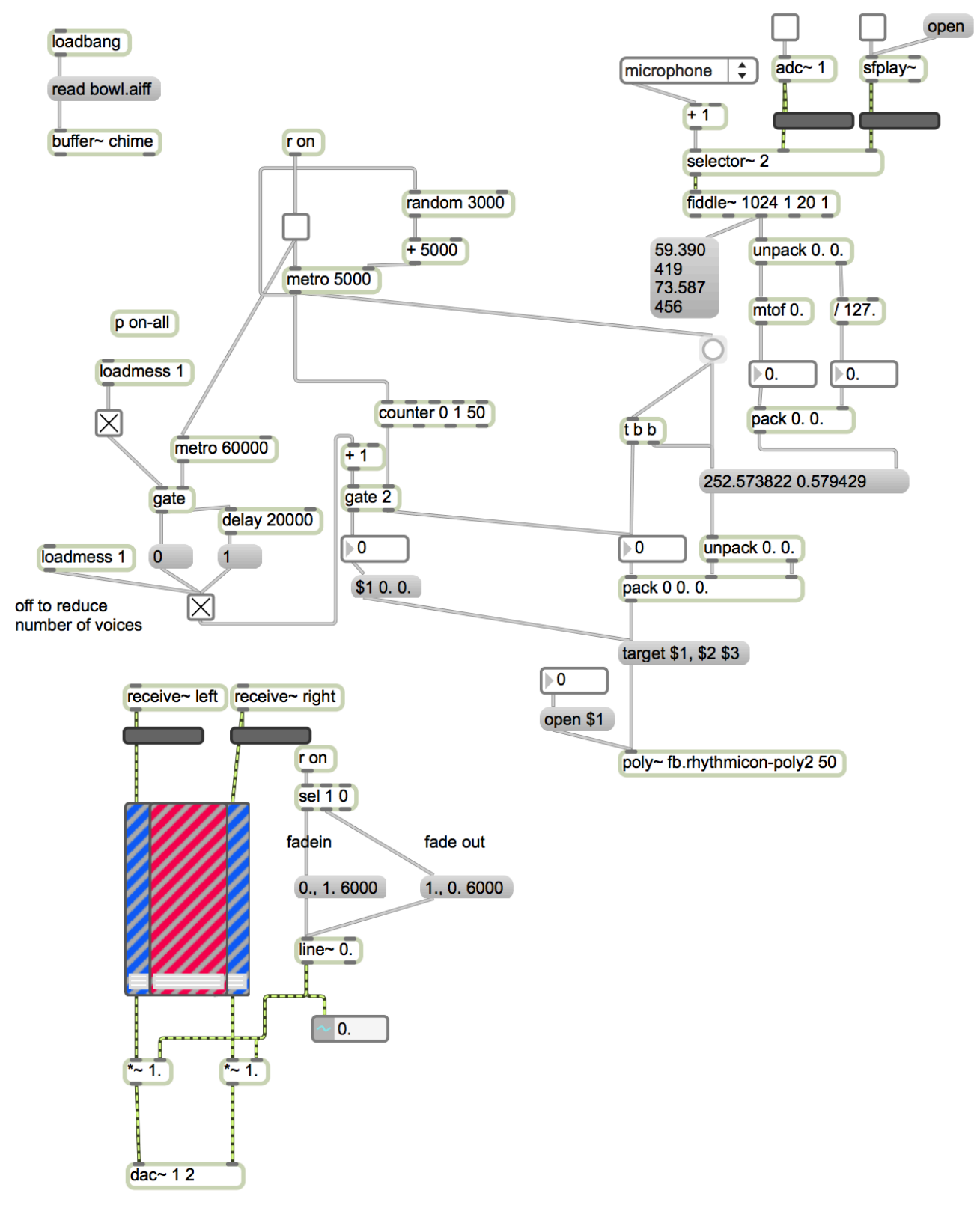

Figure 4.8 Max/MSP patch for Rhythmicon (see Appendix 1 for further details).

\subsection{Rhythmicon in the concerto}

The list of midicent values collected from OpenMusic (shown in Figure 4.3) was used to generate durations. For this purpose I created a separate patch in OpenMusic (Figure 4.9) that calculates durations proportional to the frequency in the same way that 
durations are affected by playback speed changes on magnetic tapes:

if frequency $=\mathrm{x} / 2$ then duration $=2 \mathrm{x}$

if frequency $=\mathrm{x}$ then duration $=\mathrm{x}$

if frequency $=2 \mathrm{x}$ then duration $=\mathrm{x} / 2$

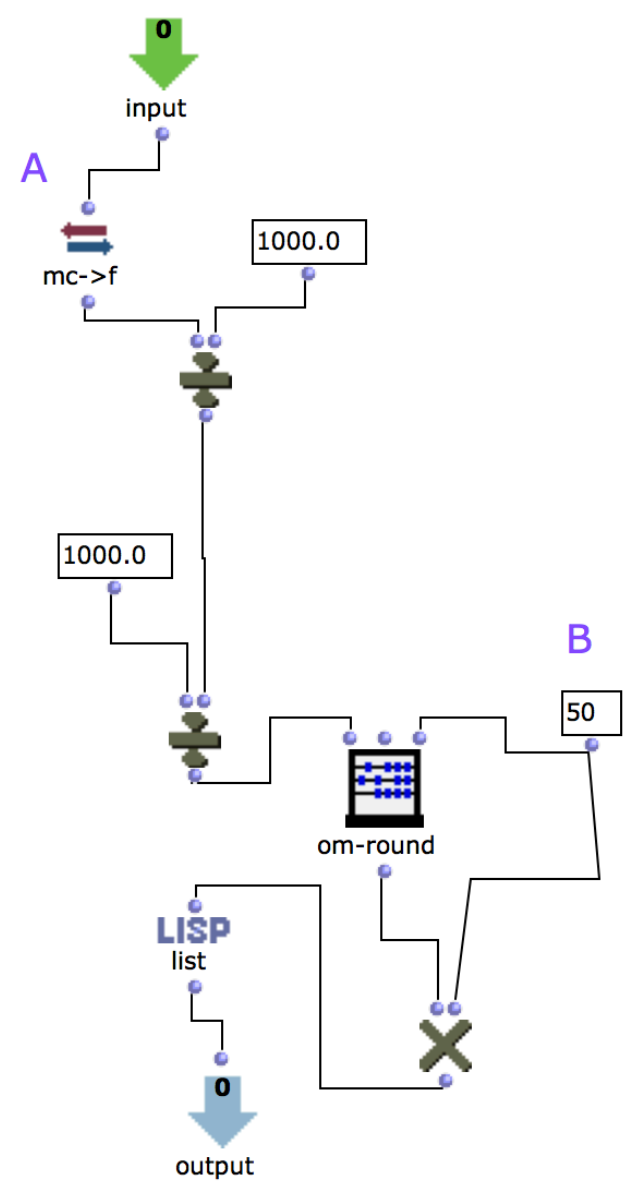

Figure 4.9 Abstraction used to assign durations to the frequencies in Collection 2.

The abstraction shown in Figure 4.9 allows the user to specify the maximum subdivision of the beat (B). A value of 50 indicates that the maximum subdivision will be one twentieth of a beat. This is calculated based on the beat value I used:

-Duration of a beat $=1000 \mathrm{~ms}$

$-1000 / 20=50$ 
I chose this maximum subdivision because I wanted accurate results, although I knew that this would present some practical problems once the values were converted to standard notation. The main patch, shown in Figure 4.10, was used to calculate how many repetitions of the note would be necessary to fill approximately 5 minutes (B and C). Each result was then inputted into a voice object, which rendered it into traditional notation.

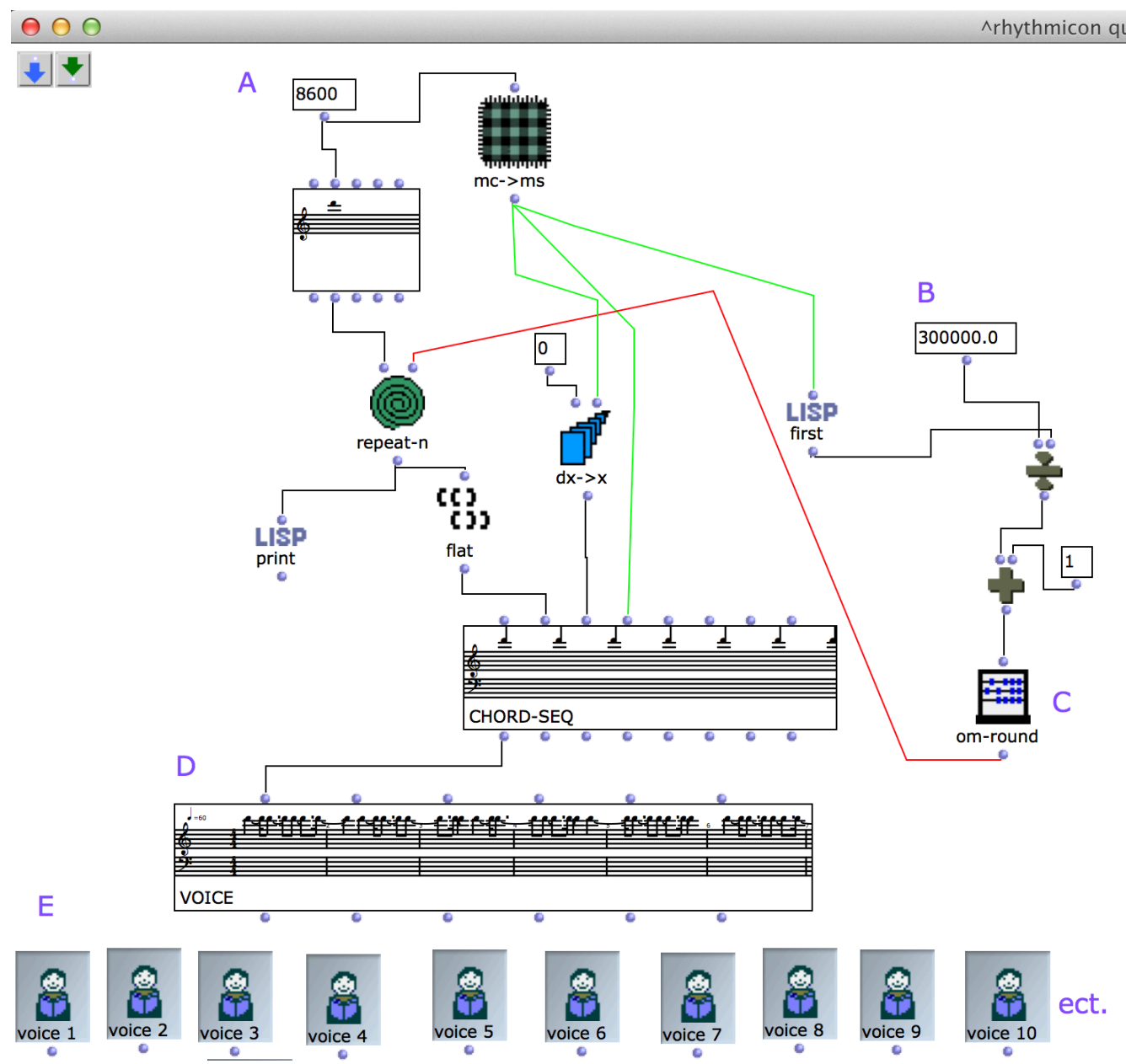

Figure 4.10 OpenMusic patch that assigns a duration to a midicent value based on its frequency and notates the result.

Figure 4.11 shows a list of all the midicent values with their duration in milliseconds. 
The 38 individual voices were then consolidated into a single score using the poly object (in a separate patch) and exported to Finale. While Cowell advocated notating each part in its own meter when using polyrhythms to eliminate the need for performers to "negate" the natural accent of the meter (Cowell 1958: 70), doing so in the concerto would have resulted in over 30 different simultaneous meters. I instead chose to notate all parts in the same meter so that the conductor would at least be able to provide regular reference points for the performers (Figure 4.12).
1. $(10050368)$
14. (8950695)
27. (7550 1561)
2. $(10000379)$
15. $(8900716)$
28. (7000 2145)
3. (9900 402)
16. (8800 758)
29. (6750 2478)
4. $(9750438)$
17. (8750 781)
30. (6500 2863)
5. (9700 451)
18. (8600 851)
31. (6200 3405)
6. $(9650464)$
19. (8500 902)
32. (5900 4050)
7. $(9600478)$
20. (8400 956)
33. (5800 4290)
8. (9550 492)
21. (8350 984)
34. (5300 5727)
9. $(9500506)$
22. (8200 1073)
35. (4750 7868)
10. (9300 568)
11. $(9200602)$
12. (9150 620)
23. (8100 1136)
24. (7950 1239)
25. (7850 1313)
13. (9050 656)
26. (7700 1432)
36. (4600 8581)
37. (4450 9357)
38. (3400 17161)

Figure 4.11 List of pitches and durations used in the rhythmicon sections. For each column the numbers represent the partial number followed by, in parenthesis, the pitch in midicents and the duration in milliseconds. 


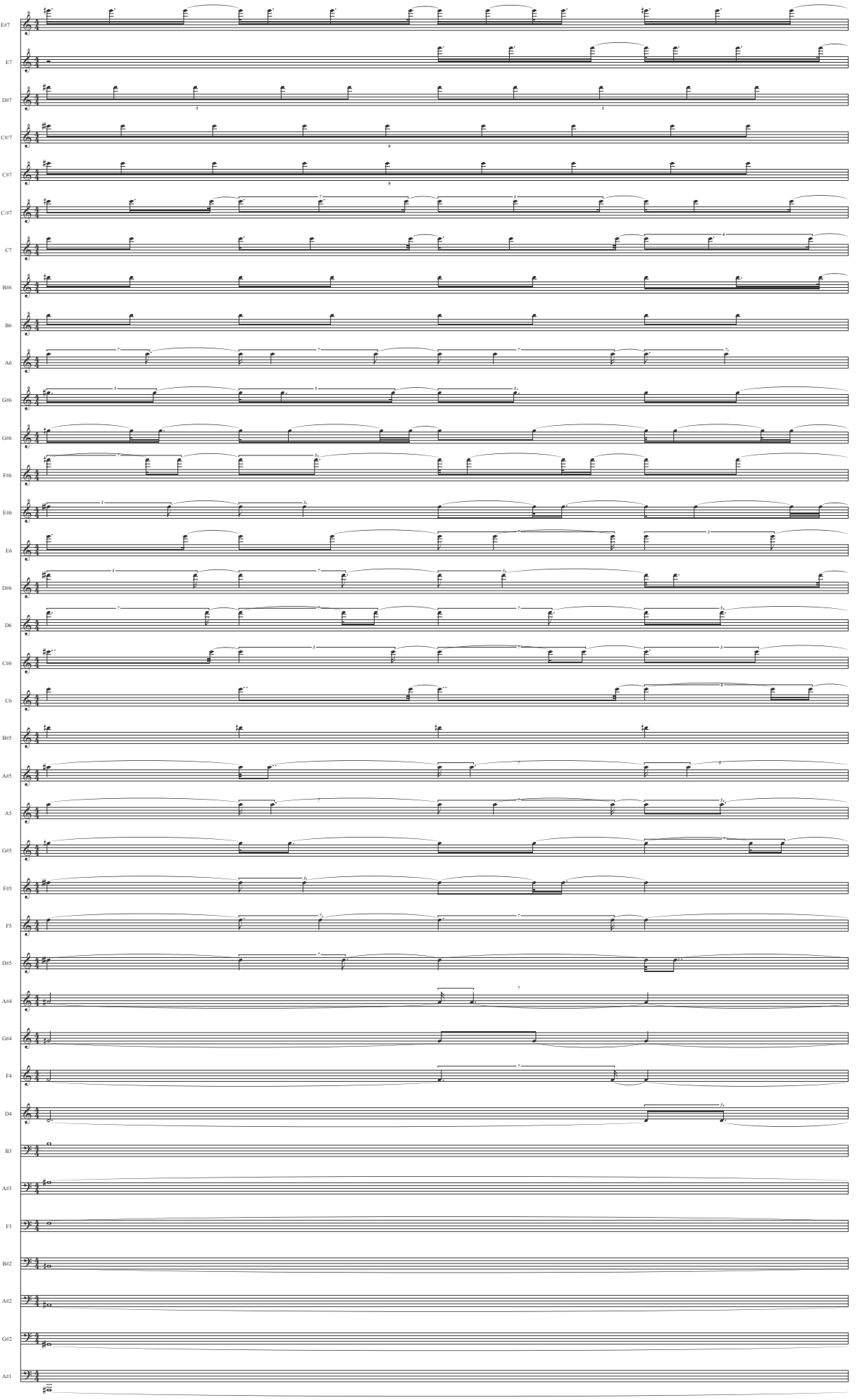

Figure 4.12 First measure of the raw score used to create the rhythmicon in d'improvviso da immobile s'illumina. 
The resulting score, shown in figure 4-12, was used only as a reference to establish durations in the actual piece. Because, however, standard music notation is ill suited for this sort of process, and because the relatively high precision level I chose led to results that were often unnecessarily complicated and impractical, I occasionally simplified the notation to make it easier for a performer to read. As an example let's take the pitch $A \sharp^{4}$. Its midicent value is 7000 , which corresponds to $466.1638 \mathrm{hz}$. If we now calculate the corresponding duration in milliseconds based on a beat value of $1000 \mathrm{~ms}$. we obtain the following:

1) $466.1638 / 1000=0.4661638$

2) $1000 / 0.4661638=2145.16871537429547$

3) 2145.16871537429547 rounded to the nearest multiple of $50(1 / 20$ of the beat $)=$ 2150

If we input these values into the voice object we get the following result:

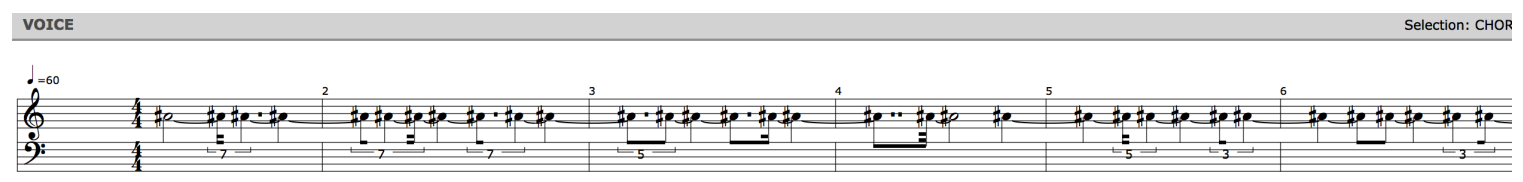

Figure 4.13 Approximation problems with the voice object in OpenMusic.

This problem could have been avoided by rounding to a different value, for example 250 , but I decided to use the same beat division for all pitches and make modifications as necessary if the results were impractical. This particular pitch was assigned to clarinet 1 . In addition to simplifying the notation, I periodically interrupted the pattern to ensure that the performer could breathe regularly. I decided to choose a much simpler rhythmic 
notation that was fairly close in length to the original, 183 milliseconds shorter to be exact. If we compare the original and the simplified version over the course of several measures, the difference becomes quite noticeable. In addition to further approximating the durations, I ultimately decided to round all pitches to the nearest semitone to make the parts easier to play. Rounding all pitches to the nearest semitone reduced the size of the chord to 28 and allowed me to split or reinforce a voice when needed. This goes to show that applying idiomatic electronic music techniques to traditional notation can be quite problematic. I diverged further from the original results by offsetting the entrances to avoid having the voices align too soon, especially as the rhythmicon unfolded. Lastly, I placed regularly recurring accents in each voice; as a result, most voices have a macro as well as a micro pulse, as shown in Figure 4.14, where the first note of each group of three is accented. The accents also serve the purpose of enlivening the otherwise quasi-robotic parts, as in Figure 4.15. What I did retain in every part is the consistency of the durations within each voice once its durations are established.

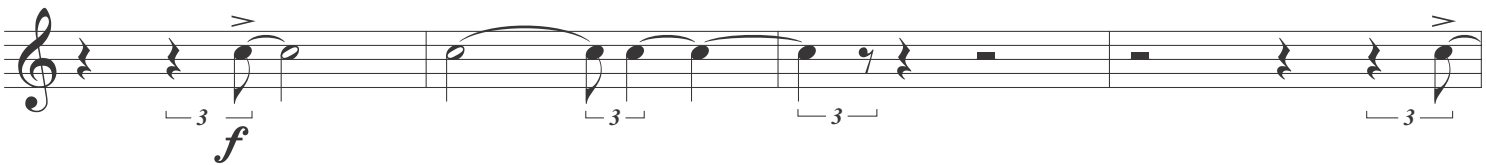

Figure 4.14 D'immprovviso da immobile s'illumina mm. 91-94. Clarinet 1.

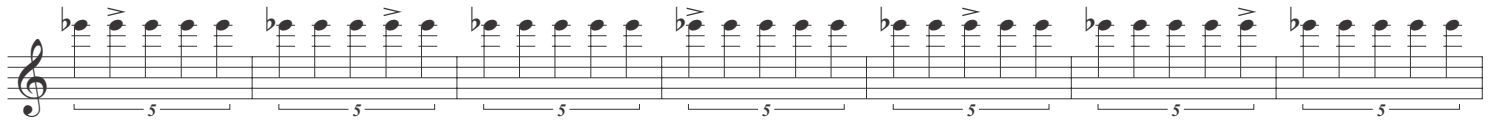

Figure 4.15 Ibid. mm. 101-107. Violin 2.

Once I collected the raw material for the rhythmicon sections, I separated the 
chord into several smaller sonorities and plotted the entrances carefully, leaving the entrance of the fundamental tone last. I composed the first draft of the rhythmicon as a gradual crescendo slowly adding voices in the order shown in Figure 4.16.

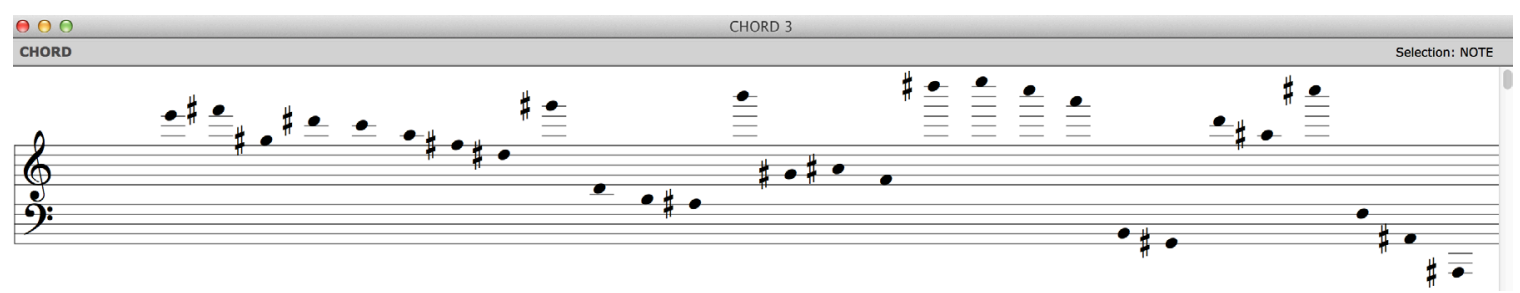

Figure 4.16 Pitches use in the rhythmicon section in order.

I then spliced the score in to smaller sections and inserted between them material based on Collection 1 so that the rhythmicon would only gradually become prominent. Measures 59-70 of the concerto (see Appendix 2) are a good example of how I delayed the crescendo of the rhythmicon by inserting materials and gestures based on Collection 1 into the rhythmicon sections. In measure 71 , the rhythmicon is interrupted by the percussion, which recalls mm. 4-7 of the concerto.

The rhythmicon becomes the prominent material at $\mathrm{m} .91$, continuing on for nearly fifty measures, its texture steadily thickening until the fundamental tone of the chord is finally heard in the tubas in $\mathrm{m} .117$, signaling the arrival of the climactic point. The low B $b^{1}$ is played by both tubas and is also doubled by the double bass 2 , while being reinforced one octave higher by double bass 1 and two octaves higher by bassoon 2 and horn 1. By suddenly becoming the loudest pitch, the fundamental tone provides a sense of meaning to the otherwise chaotic texture, revealing a large-scale hierarchy that was hitherto disguised. The instruments occasionally align with one another, but are 
otherwise asynchronous. But when the rhythmicon comes back after the long cadenza in m. 176, all voices are finally aligned, quickly dissipating again into an asynchronous texture. The return of the chord structurally defines the beginning of the final section. 


\section{SPATIALIZATION}

\subsection{Introduction}

One of the great advantages of electronic music over traditional acoustic music is that sounds are not assigned to a specific physical location but can be heard from any place where a loudspeaker is placed. A sound can come from one direction and gradually or suddenly move to another, or come from multiple directions at once. Even in electronic music that incorporates live instruments (known as electro-acoustic music), the sound produced by the live instrument or instruments can be redirected to a loudspeaker placed in any chosen direction. It is common in both electronic and electro-acoustic music to surround the listener with speakers to take advantage of spatialization possibilities.

\subsection{Spatialization in Western Music}

Experimentations with spatialization are nothing new. The concept in its basic essence can be traced back to the practice of alternatim singing in the Byzantine and Christian liturgy, a tradition that still survives today (Hiley and Lingas, 2001). The practice is by no means limited to a single geographic location or historical time. "Call and response" is a typical feature of African-American work songs, a trait that has not surprisingly been inherited by jazz (Kernfeld "call and response"). By singing or playing in alternation, members of the group naturally spatialize the music in more or less obvious ways depending on where the musicians are placed. In the $15^{\text {th }}$ and $16^{\text {th }}$ centuries, the responsorial and antiphonal practices used in chants were adapted to polyphonic music (Solomon 2007: 27). Composing for cori spezzati or broken choirs, 
was especially popular in Venice, and was practiced and passed on by many composers such as Willaert, Lassus and Palestrina, culminating in the works of Giovanni Gabrieli.

Gabrieli's polychoral music was highly influential in his time and although the practice lost much popularity in Italy by 1630 , composers who had studied in Venice exported it to Rome, Spain, Germany, and England where it was further developed and reached very high levels of complexity especially in Germany and in Rome (Arnold and Carver, 2001). By the $19^{\text {th }}$ century, spatialization was used rarely and was generally associated with the stile antico, typically reserved for sacred choral music, which was historically conservative (Solomon 2007: 32). Among the relatively rare examples of spatial works in the $18^{\text {th }}$ and $19^{\text {th }}$ centuries are Mozart's Serenade No. 8 (Notturno) in D major for Four Orchestras, K. 286 and Berlioz's massive Requiem in which four brass groups are placed in the four corners of the hall.

The $20^{\text {th }}$ century saw a renewed interest in spatialization as a "critical feature or sonic design" (Solomon 2007). There are many notable examples including works by Karlheinz Stockhausen, Henry Górecki, and especially Henry Brant, who composed hundreds of spatial works featuring many different kinds of techniques. In Brant's spatial works, the physical arrangement of the performers is very carefully planned. He usually asks that the pieces not be performed if the indicated setup cannot be followed (Brant 2002). ${ }^{11}$ In discussing his spatial works in an interview with Frank J. Oteri, Brant

\footnotetext{
${ }^{11}$ See for example the performance notes for An American Requiem where he writes: "For reasons explained in detail below, performance must not be attempted with all the instruments placed on stage, or all together in any single area." In Henry Brant, An American Requiem, (New York : Henmar Press : C.F. Peters Corp., [1980], 1976.)
} 
acknowledged the influence of Gabrieli, Berlioz, and Ives and the impact of having heard Berlioz's requiem in the hall where it was premiered in Paris (Brant 2002). ${ }^{12}$

Brant's spatial experimentations include wide separation of performers, placing performers on different levels, symmetrical pairings of ensembles, or requesting that performers move during performance. Brant typically would assign specific gestures and motives to the instrument or instruments of a particular location, as he believed that the music played by each group "must be highly individualized" (Brant 2002). He purposefully avoided moving motives around as that might disrupt the individuality. To enhance the musical contrast, he often juxtaposed free improvisation with strictly notated music or had instruments or groups play in contrasting styles. Not surprisingly, Brant music frequently uses jazz idioms and ensembles (Harley 1994: 251-2).

Charles Ives had previously experimented with the idea of separating groups stylistically as well as physically in his work Three Places in New England (1935) in which groups play different tunes and styles at the same time. Stylistic contrast is also the prominent in The Unanswered Question (1953), in which Ives has three groups, a woodwind quartet, a trumpet, and a string quartet, play different styles and tempos at the same time.

Karleinz Stockhausen made many important contributions to spatial music. Stockhausen's initial experiments with spatialization came as a result of his exposure to musique concrète concerts during his studies in Paris as well as his involvement with serialism (Harley 1994: 152). While the initial focal point of serial composers was 
limited to pitch relationships, second-generation serialists such as Stockhausen, extended the concept to other parameters such as dynamics, timbre, rhythm, and form. In the work Gruppen für drei Orchester (1955-57), Stockhausen used spatial separation to articulate and clarify the complex textures (Harley 1994: 155). Stockhausen's tape piece Gesang der Jünglinge (1958) was the first electronic piece to serialize physical location of sound. The first version of the piece was recorded in five tracks, even though multi-track players could only play up to four tracks at the time. In the first performance the fifth track had to be played by a separate device (Smalley 2001: 10).

Stockhausen's experiments with sounds moving in space led him to compose the well-known Helikopter-Streichquartett (1992/93), for string quartet, four helicopters, and television and audio relay, in which the performers play their part while flying in separate helicopters. He also designed a performance space that consisted of a "spherical chamber, fitted all around with loudspeakers" (Stockhausen 1959/1961: 69) that was built as the German Pavilion at the 1970 World Expo in Osaka, Japan (Figure 5.1). The audience was placed on a grid just below the center of the sphere, and 50 groups of loudspeakers were arranged around the space (Föllmer: Karlheinz Stockhausen «Spherical Concert Hall»). But already in 1958, Le Corbusier and Iannis Xenakis had designed the Philips Pavilion for the Brussels World Fair in 1958. The space utilized over 300 loudspeakers that were used to project Edgar Varèse's piece Poème Electronicque (Treib 1996). ${ }^{13}$

\footnotetext{
13 There was never an exact count made of the speakers used in the pavilion, and estimates vary between 150 and 450. According to Treib, the most accurate estimates are 325 (Treib 1996: 49).
} 


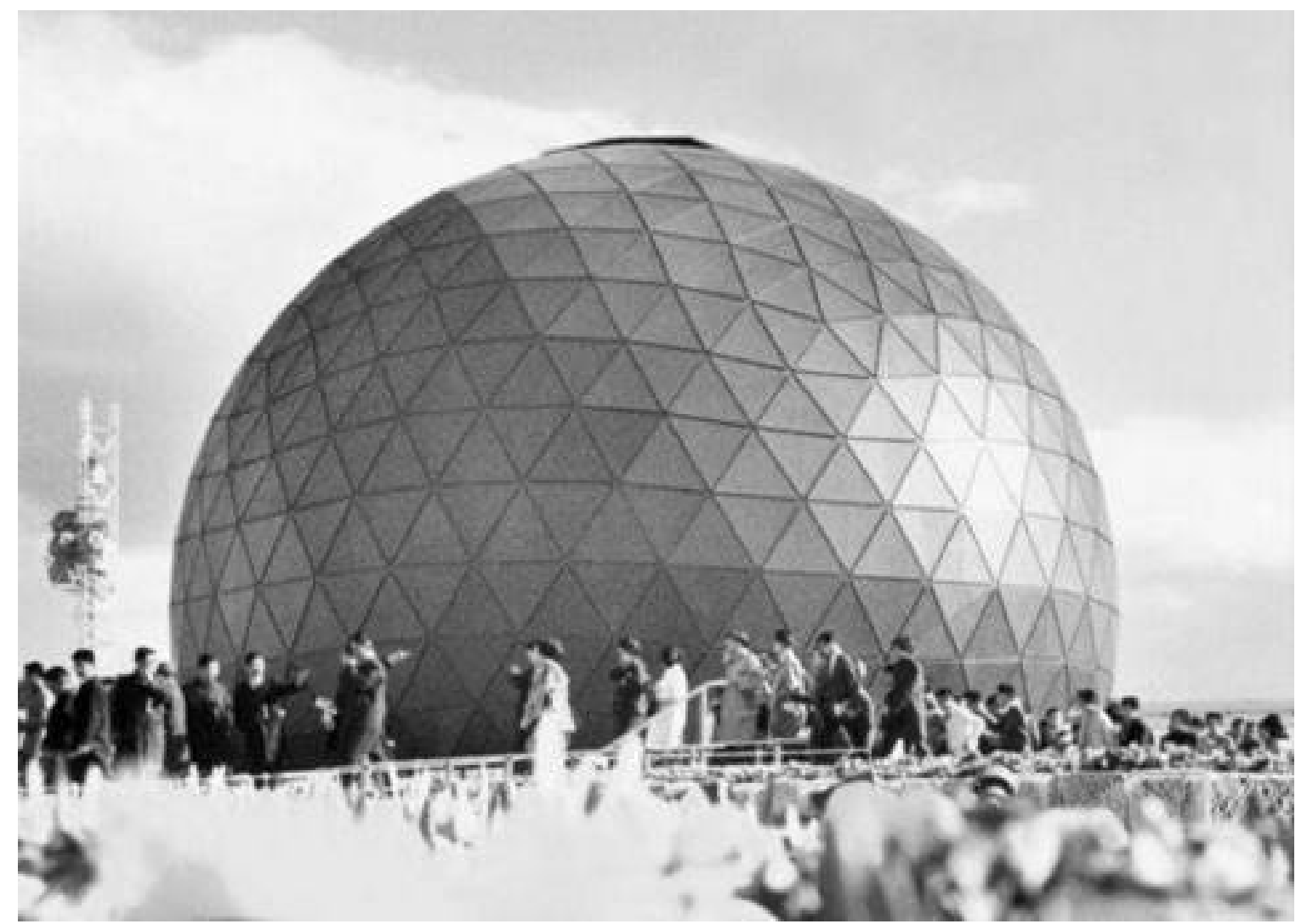

Figure 5.1 Spherical Concert Hall, built for the 1970 German pavilion at the Osaka World Fair. Photo ${ }^{\circ}$ Karlheinz Stockhausen

The spatialization of sound has been an essential component of electronic music since its origins. While early electro-acoustic works were monophonic, some were recorded on separate tracks so that they could be performed using different loudspeakers. By the early 60 s stereo became the norm, although this did not mean that sound was diffused the way it is today, but rather that they were two-track pieces. Around the same time the quadraphonic (four-track) format also became widely used (Emmerson and Smalley "Electro-acoustic music"). In a quadraphonic setup, the four speakers are normally placed around the listeners effectively surrounding them with sound. This allows the composer to create the illusion that sound is moving around or travelling from 
one place to another. Alternative setups might include a speaker hanging from the ceiling enabling composers to create the illusion of vertical as well as horizontal movements (Manning 2013, 26). In the late 1990s, the eight-channel format also became popular, permitting an even more realistic surround-sound effect. In addition, computer programs and processors were developed that made it possible to create, even using a simple stereo setup, the illusion of sound travelling smoothly from one side to the other, or coming from above or below, an effect that can be greatly enhanced with visual effects (Emmerson and Smalley).

\subsection{Spatialization in D'improvviso da immobile s'illumina}

The setup of the instruments in D'improvviso da Immobile S'illumina was undoubtedly influenced by my exposure to electronic music during my studies at FIU. When I began to envision the piece from a spatial perspective, it was immediately clear to me that I needed to use a non-traditional orchestral arrangement. In traditional orchestras the sound of the individual instruments or sections is bound to a specific spatial location. For instance, if a work for orchestra contains two flute solos, they both will be heard coming from the same location, unless special arrangements are made for a separate flute player to be placed elsewhere or for the flute player to move between solos. Many composers give the performers special instructions as Thea Musgrave did, for example, in her Clarinet Concerto (1969) by charting a trajectory for the soloist who is asked to move to different locations on the stage throughout the piece.

In electronic music, the simplest way to pan a sound is to slowly turn up the volume of one speaker while turning down the other. Although doing this will naturally 
be far less effective than using an especially designed algorithm, it is relatively easy to realize with an orchestra by having at least two players for each instrument placed on opposite sides of the stage thus creating a simple stereo effect. For this reason, I divided the orchestra into two main symmetrical groups. The two groups naturally needed to be physically separated or else the effect between adjacent instruments would be completely lost. In addition to the two orchestras, I included piano, and three sets of percussions arranged symmetrically behind the two orchestras, which are not considered part of either orchestra. Figure 5.2 shows the seating chart of the concerto.

perc. 2

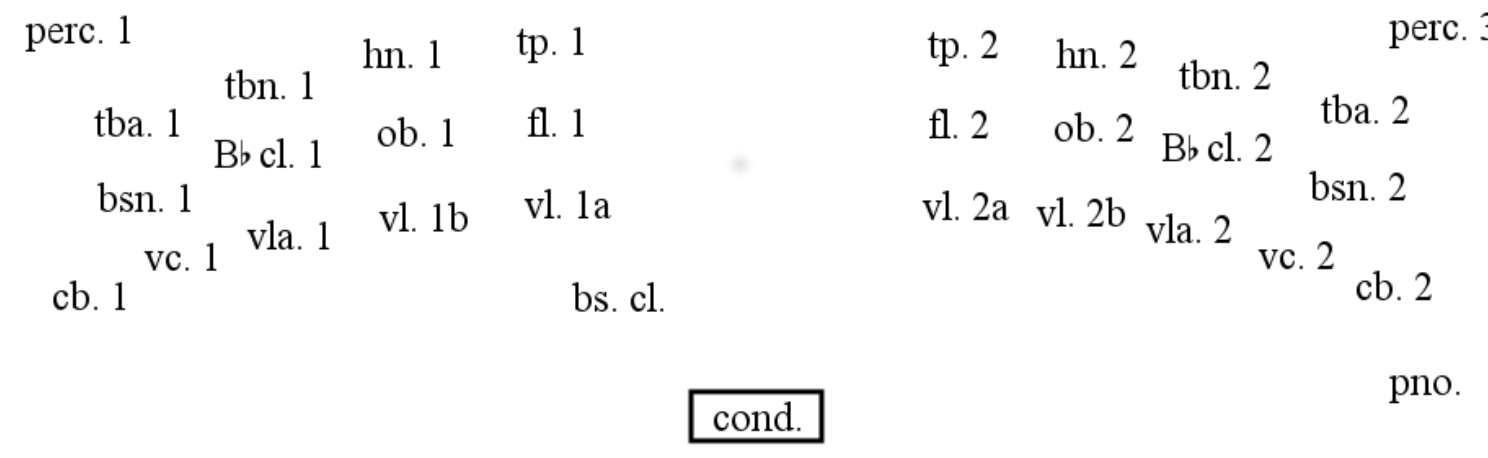

Figure 5.2 Seating chart for the D'improvviso da immobile s'illumina.

I had two main objectives with respect to spatialization: the first was the ability to pan a sound from one direction to the other. The second was to have a relatively wide angle from which sounds could come from. The second aspect was especially important for the rhythmicon sections. Figure 5.3 shows an instance of a sound travelling from one side to the other. 


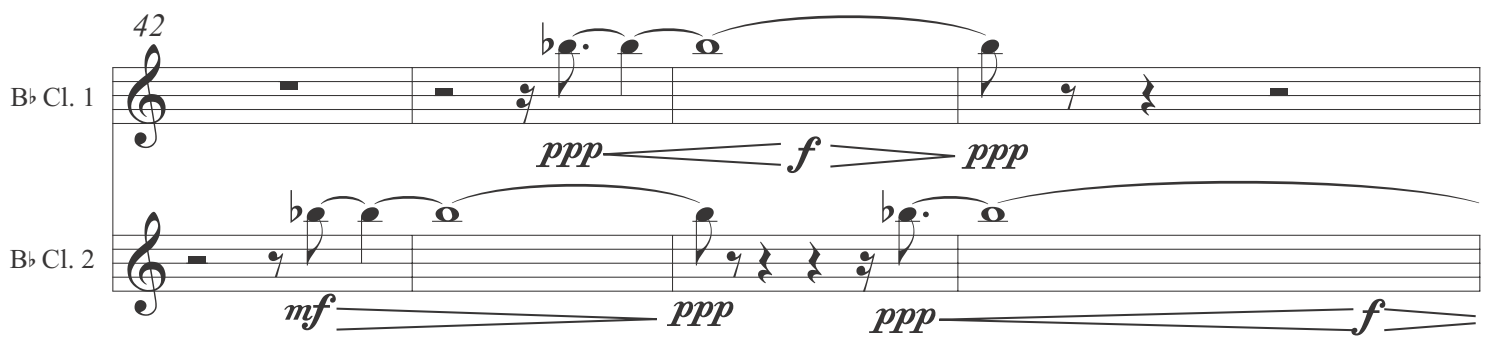

Figure 5.3 Cross fading in D'improvviso da immobile s'illumina.

As can be seen in the example, the spatial effect is obtained by cross-fading the two clarinet parts. I chose to use clarinets for this passage because of the instrument's idiomatic ability to control subtle changes in volume. Figure 5.4 shows the climactic point of the rhythmicon section. Here while most of the notes of the chord have a specific location, the pitches that are doubled are offset so that the attacks are heard coming from different directions. 


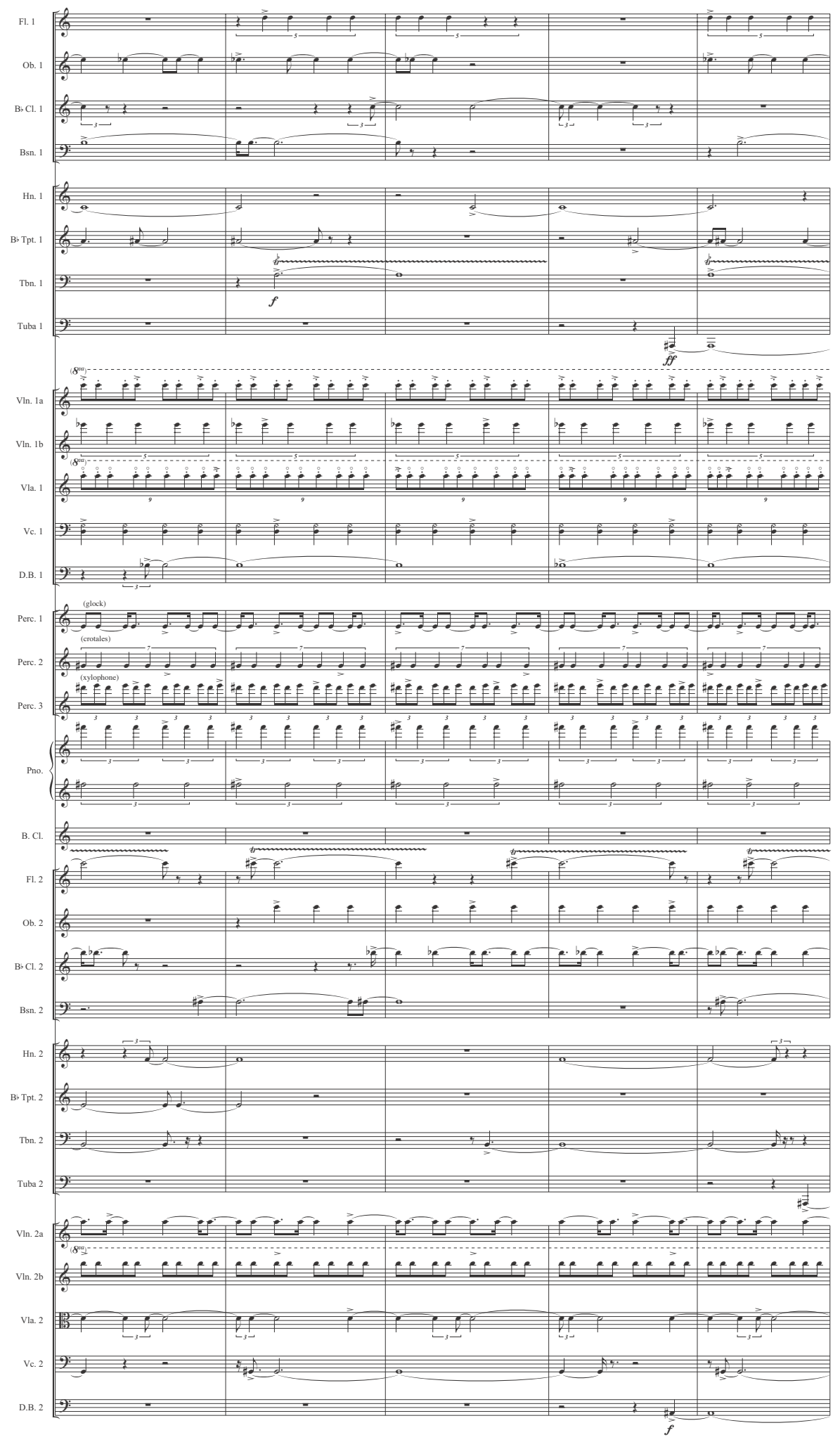

Figure 5.4 D'improvviso da immobile s'illumina mm. 114-118. 


\section{CONCLUSION}

D'improvviso da immobile s'illumina was inspired by my personal attempt to find a balance between the perpetually coexisting antagonistic forces that govern every aspect of our lives. Each human being must learn to balance the forces of good and evil, gain and loss, happiness and sadness, and must ultimately learn to master acceptance. A composer has to find a balance between rationality and intuition, a soloist and orchestra, and ultimately make choices. Often compositions have a way of taking on a life of their own and naturally deviate in various ways from the original plan. This unpredictability is one of the many fascinating aspects of a composer's work.

"It is not merely the neurotic whose right hand does not know what the left hand is doing. This predicament is a symptom of a general unconsciousness that is the undeniable common inheritance of mankind."

-Carl G. Jung 


\section{BIBLIOGRAPHY}

Arnold, Denis and Anthony F. Carver. 2001. "Cori spezzati." Grove Music Online. Oxford Music Online. Oxford University Press.

http://www.oxfordmusiconline.com/subscriber/article/grove/music/06486 (accessed July 10, 2013).

Baron, Andrew and Mike Buffington. "1932 Rhythmicon." RCATheremin.com. http://rcatheremin.com/32rhythmicon.php_(accessed August 5, 2013).

---. "1960s Rhythmicon.” RCATheremin.com. http://rcatheremin.com/60rhythmicon.php (accessed August 5, 2013).

Brant, Henry. 2002. "Spaced out with Henry Brant." Interview by Frank J. Oteri (October 4, 2002). NewMusicBox 4, no. 9. http://www.newmusicbox.org/articles/spaced-out-with-henry-brant/ (accessed July 11, 2013)

Chowning, John. 1993. Turenas, Stria, Phoné, Sabelithe. Wergo Germany. B00008G1SW. Compact Disc.

Föllmer, Golo. "Karlheinz Stockhausen «Spherical Concert Hall»." Media Art Net (Media Kunst Netz). http://www.medienkunstnetz.de/works/stockhausen-imkugelauditorium/ (accessed August 11, 2013).

Gubaidulina, Sofia.1989 (@1991).Hommage à T.S. Eliot: for soprano and octet. Hamburg: H. Sikorski.

---. 2009 (@1997). Concerto for Viola and Orchestra. New York, NY: G. Schirmer, Inc.

Harley, Anna Maria. 1994. "Space and Spatialzation in Contemporary Music: History and Analysis Ideas and Implementations." PhD diss., McGill University.

Hiley, David and Alex Lingas. 2001. "Alternatim." The Oxford Companion to Music. Oxford Music Online. Oxford University Press. http://www.oxfordmusiconline.com/subscriber/article/opr/t114/e215 (accessed July 10, 2013).

Ives, Charles. (C1953. The Unanswered Question. Hamburg: Peer, cop.

---. @1935 and 1976. Three Places in New England: a New England Symphony. Byrn Mawr, PA: Mercury Music.

Jung, Carl G. 1968. “Approaching the Unconscious.” In Man and His Symbols, ed. Carl G. Jung. New York: Dell Publishing. 
Kernfeld, Barry "Call and response." The New Grove Dictionary of Jazz, 2nd ed. Grove Music Online. Oxford Music Online. Oxford University Press.

http://www.oxfordmusiconline.com/subscriber/article/grove/music/J072500 (accessed July 10, 2013).

Kise, Lyudmila. 2011. "Part 1: Sofia Gubaidulina's approach to pitch centricity in Two Paths, Music fo two Violas and Orchestra a Dedication to Mary and Martha (1999). Part 2: Concerto for Clarinet and Orchestra." University of Utah.

Manning, Peter. 2013. Electronic and Computer music. Fourth ed. New York: Oxford University Press.

Mathews, Paul. 2006. Orchestration : An Anthology of Writings. New York: Routledge.

Musgrave, Thea. 1968. Clarinet Concerto. London: J. \& W. Chester, Ltd.

Polansky, Larry. 1983. "Spectral CANON for CONLON Nancarrow," The Early Works of James Tenney.

http://eamusic.dartmouth.edu/ larry/published_articles/tenney_monograph_sound ings/ (accessed 5, August 2013). Originally published in Soundings 13. Edited by Peter Garland. Soundings Press (1984).

Rose, François. 1996. "Introduction to the Pitch Organization of French Spectral Music." Perspectives of New Music 34 No. 2 (Summer). 6-39.

Simon Emmerson and Denis Smalley. "Electro-acoustic music." Grove Music Online. Oxford Music Online. Oxford University Press. http://www.oxfordmusiconline.com/subscriber/article/grove/music/08695 (accessed July 12, 2013).

Smalley, John. 2000. "Gesang der Jünglinge: History and Analysis.” Karlheinz Stockhausen's Gesang der Jünlinge (1956). http://www.music.columbia.edu/masterpieces/notes/stockhausen/GesangHistorya ndAnalysis.pdf .

Solomon, Jason Wyatt. 2007. "Spatialization in Music, the Analysis and Interpretation of Spatial Gestures." PhD diss., University of Georgia. The interview is also included in Mathew's Orchestration: An Anthology of Writings.

Treib, Marc. 1993. "Space Calculated in Seconds: the Philips Pavillion, Le Corbusier, Edgar Varèse.” Princeton, New Jersey: Princeton University Press. 
Wannamaker, Robert. 2012. "Rhythmicon Relationships, Farey Series and James Tenney's Spectral CANON for CONLON Nancarrow". Music Theory Spectrum. Vol. 34/1 (Fall): 48-70. 


\section{APPENDIX 1 - OPENMUSIC AND MAX/MSP PATCHES}

8.1 OpenMusic Patches 


\subsubsection{Interpolation patch}
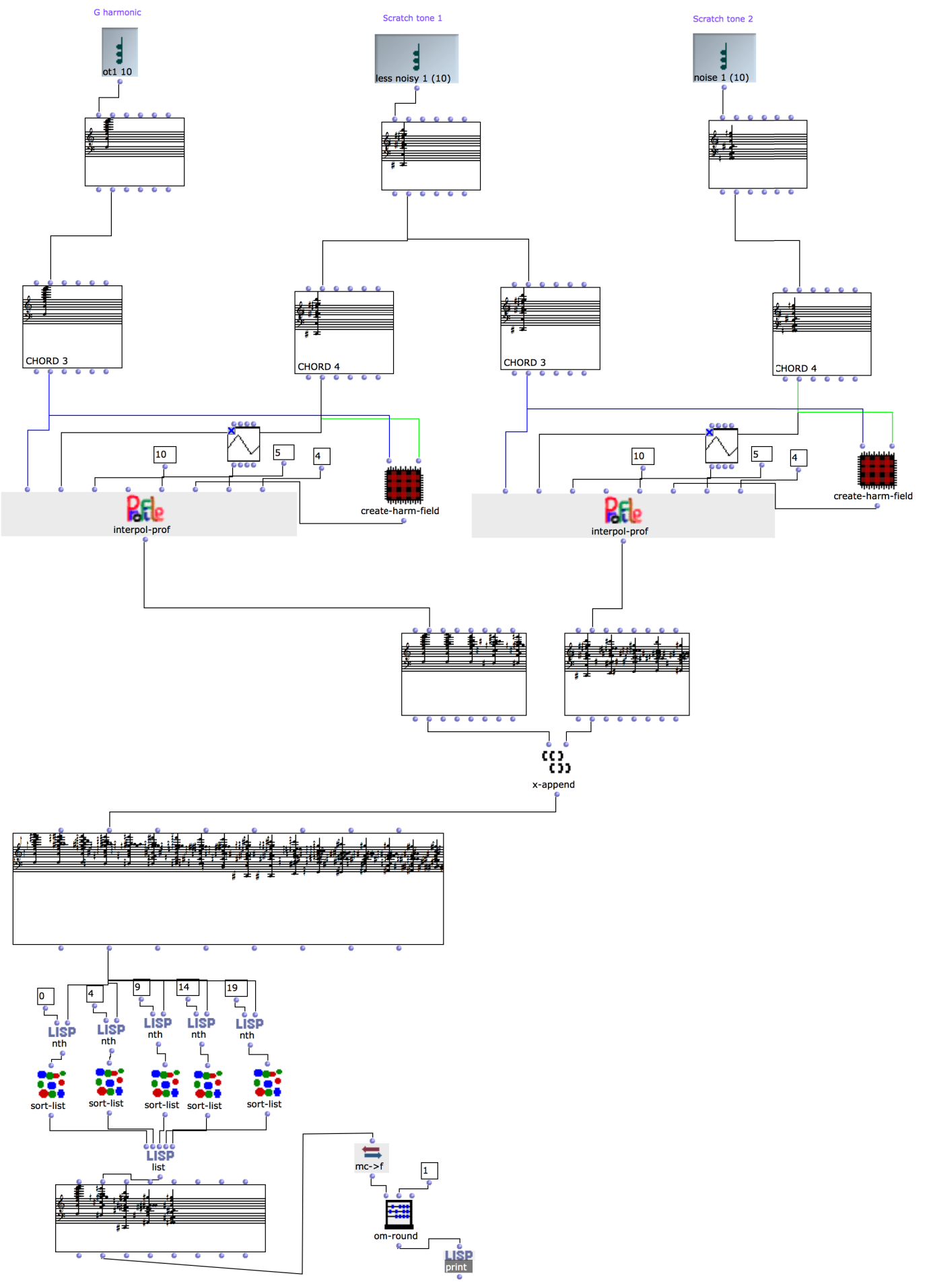


\subsubsection{1 create-harm-field subpatch}

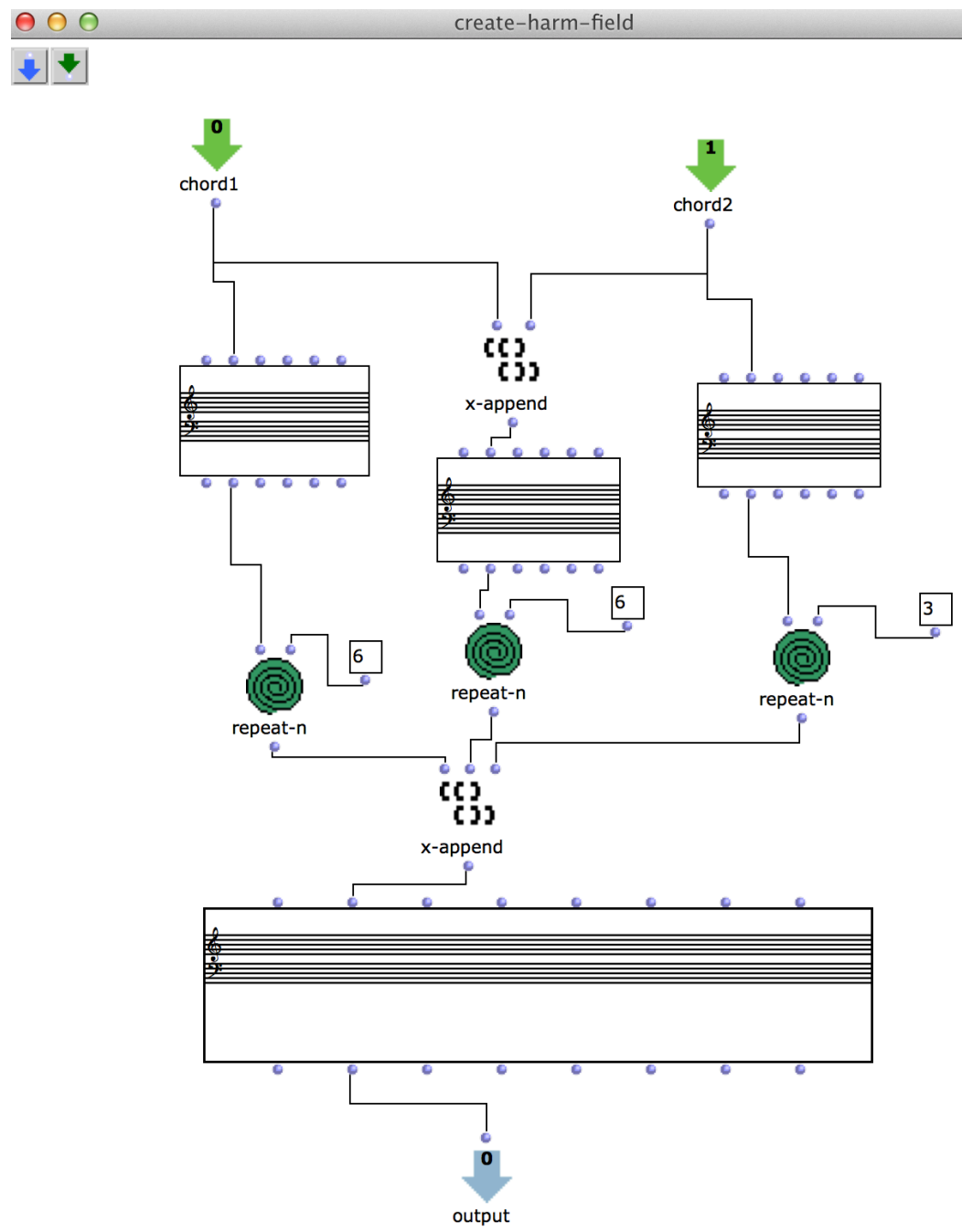




\subsubsection{Patch used to calculate subsets of hexachord 1}

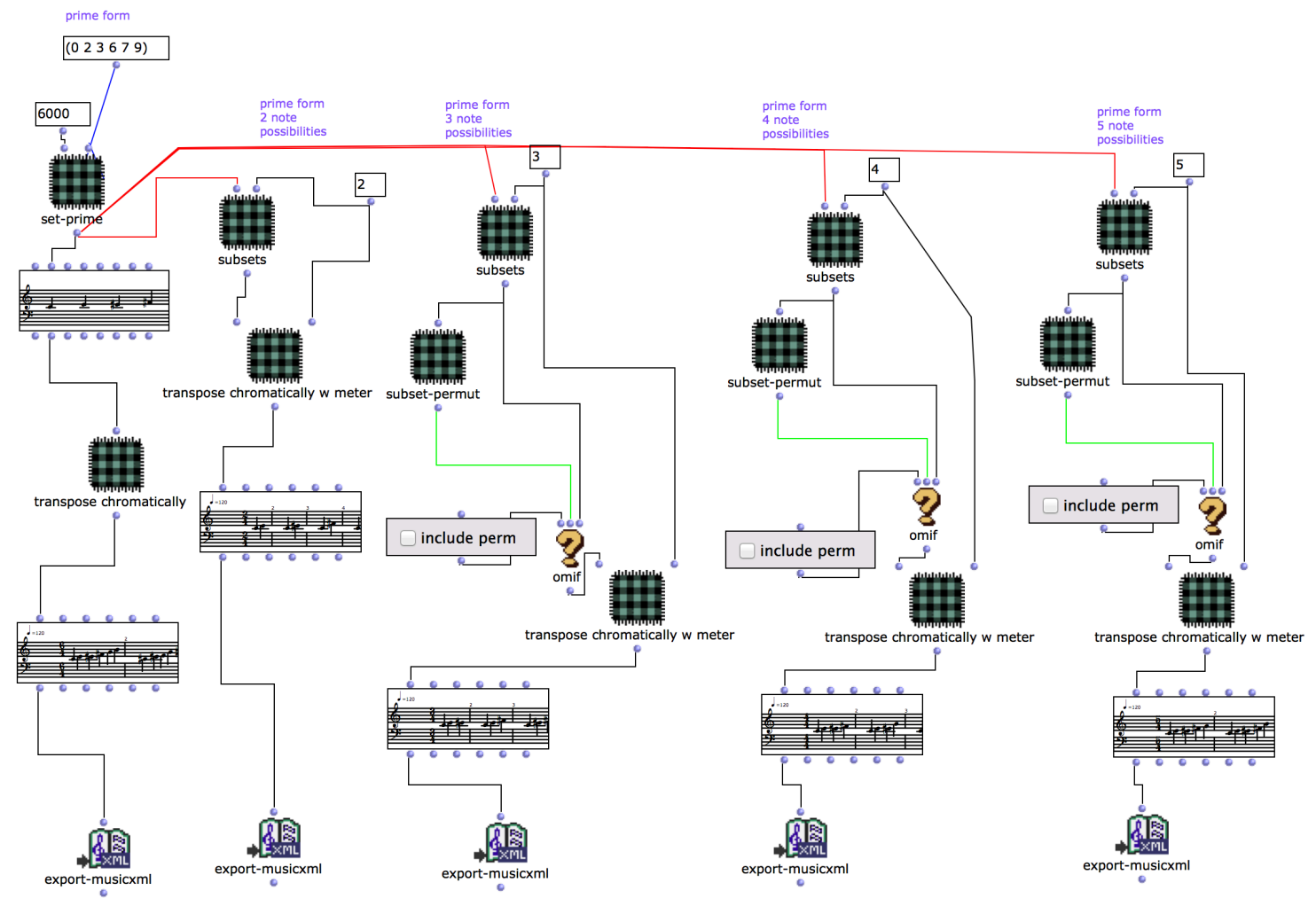




\subsubsection{Subsets and OM Loop subpatches contents}

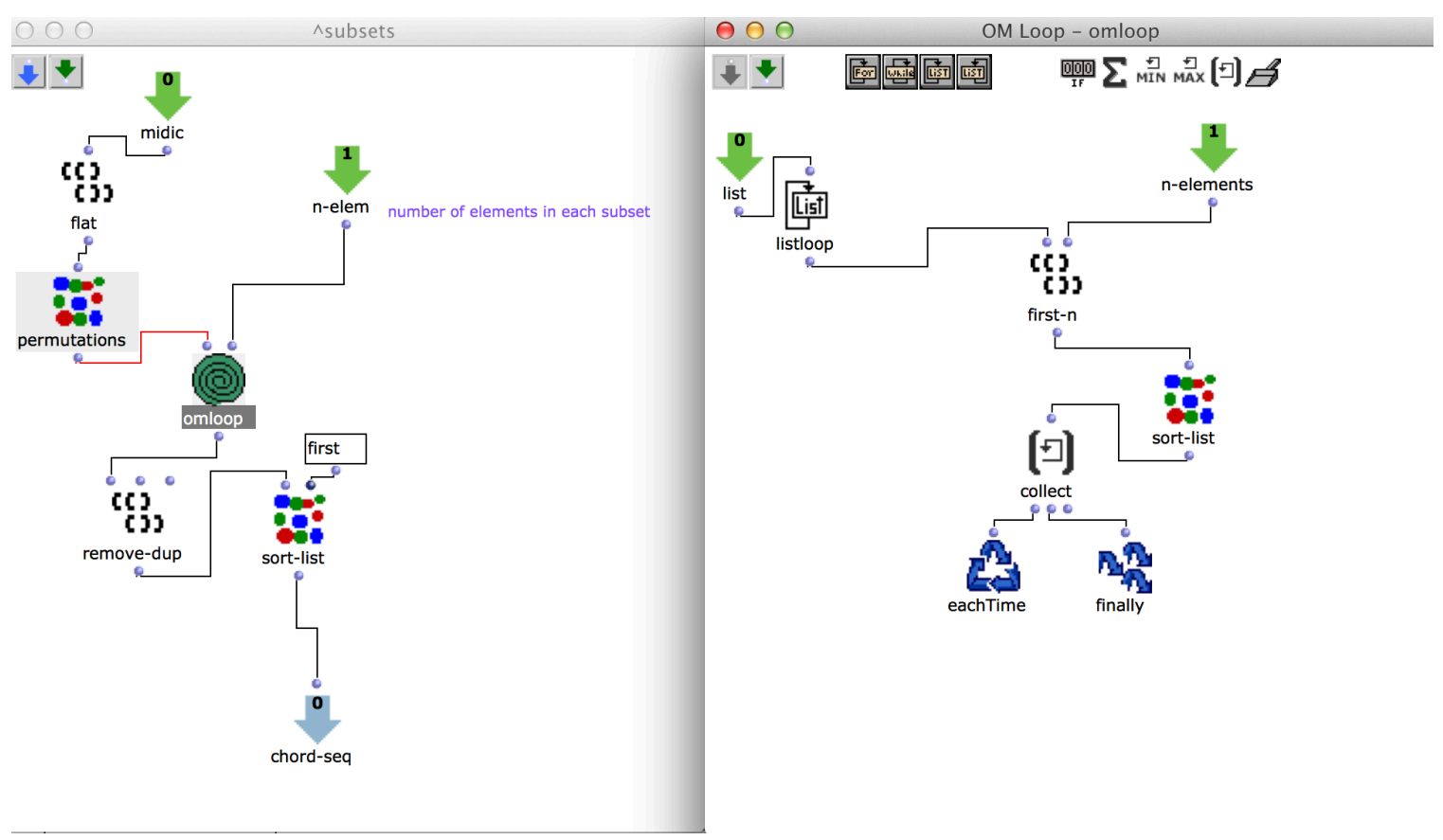




\subsubsection{Interval Multiplier}

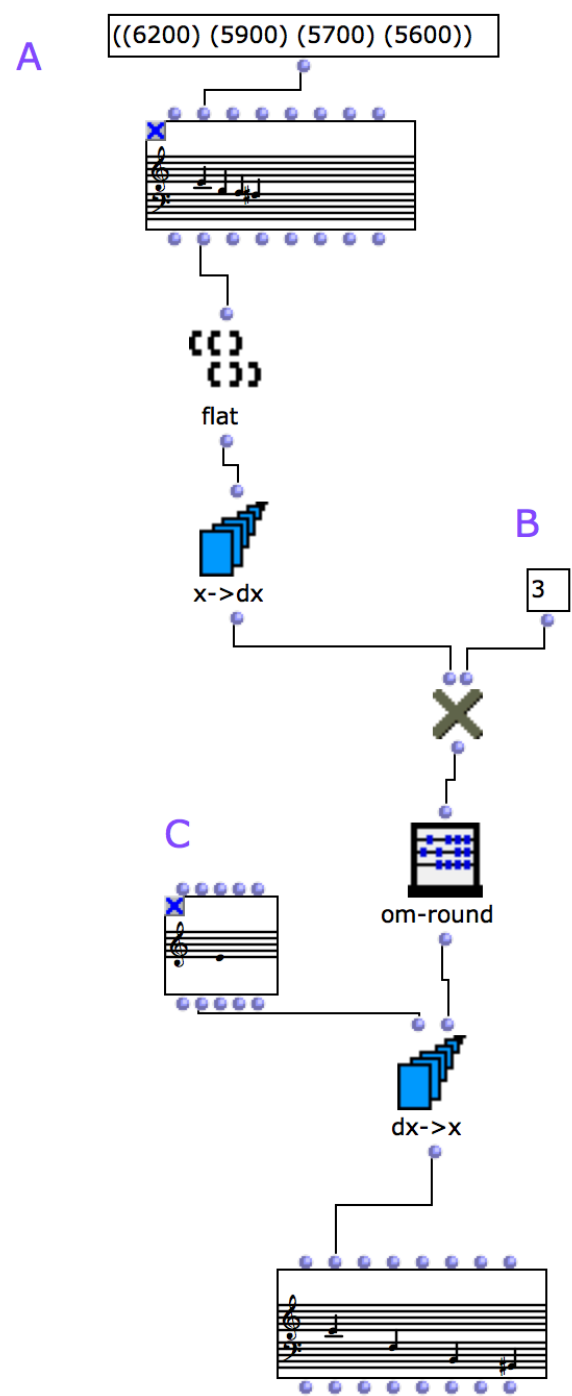




\subsubsection{Half-step-expander}

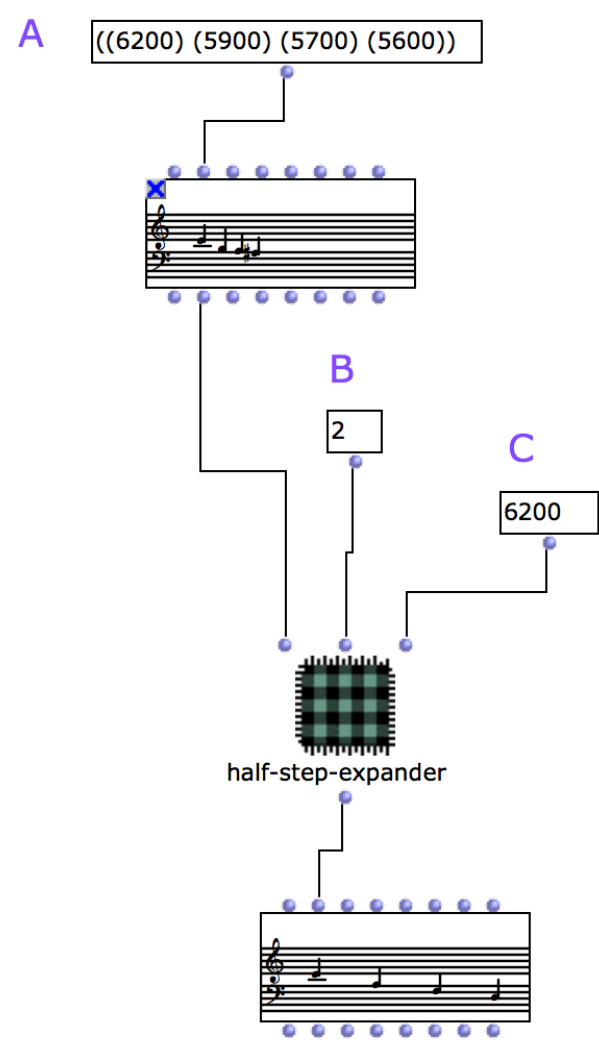


8.1.4.1 Half-step-expander, abstraction and OM Loop contents

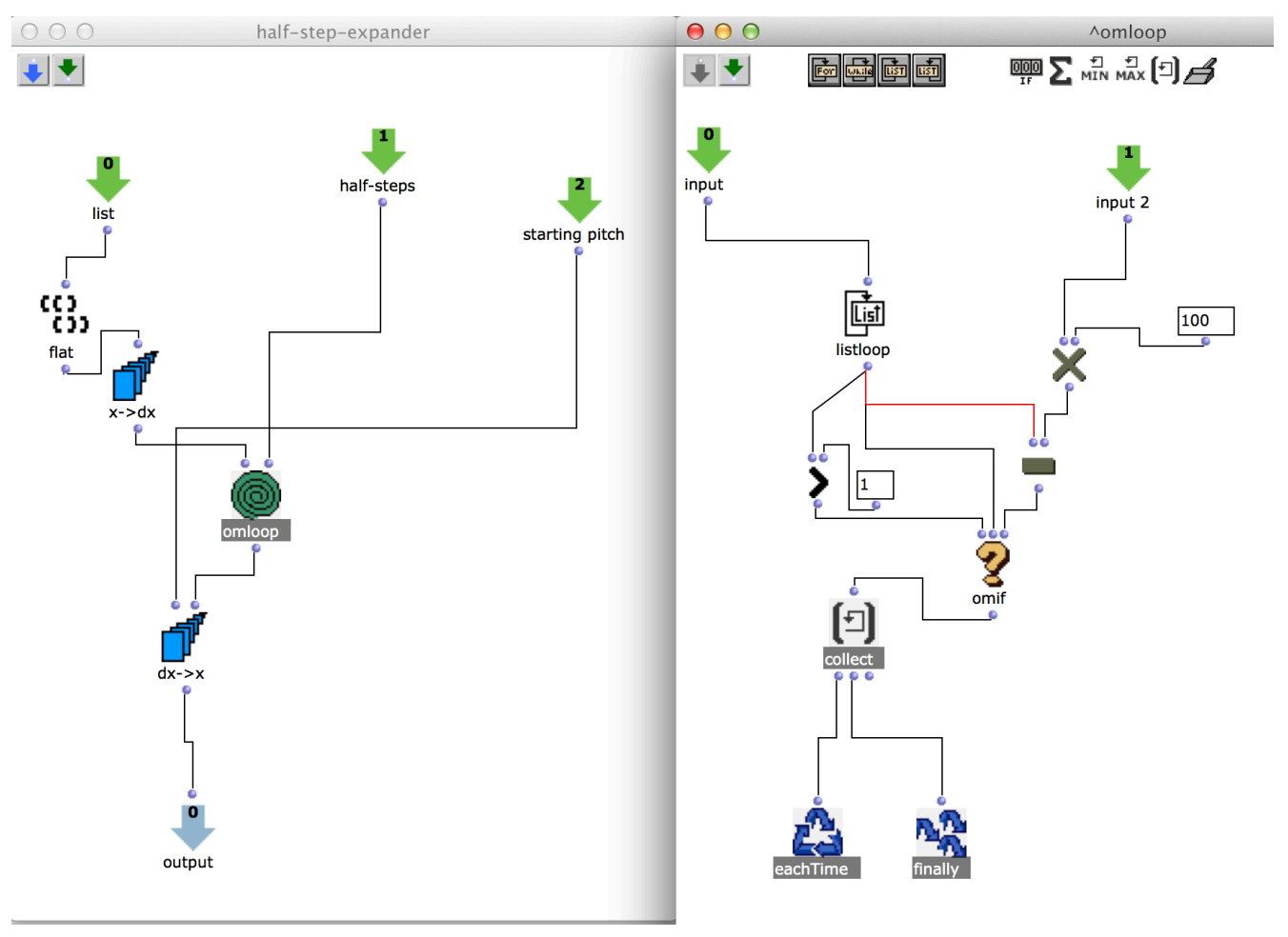




\subsection{Max/MSP patches}

\subsubsection{Rhythmicon - main patch}

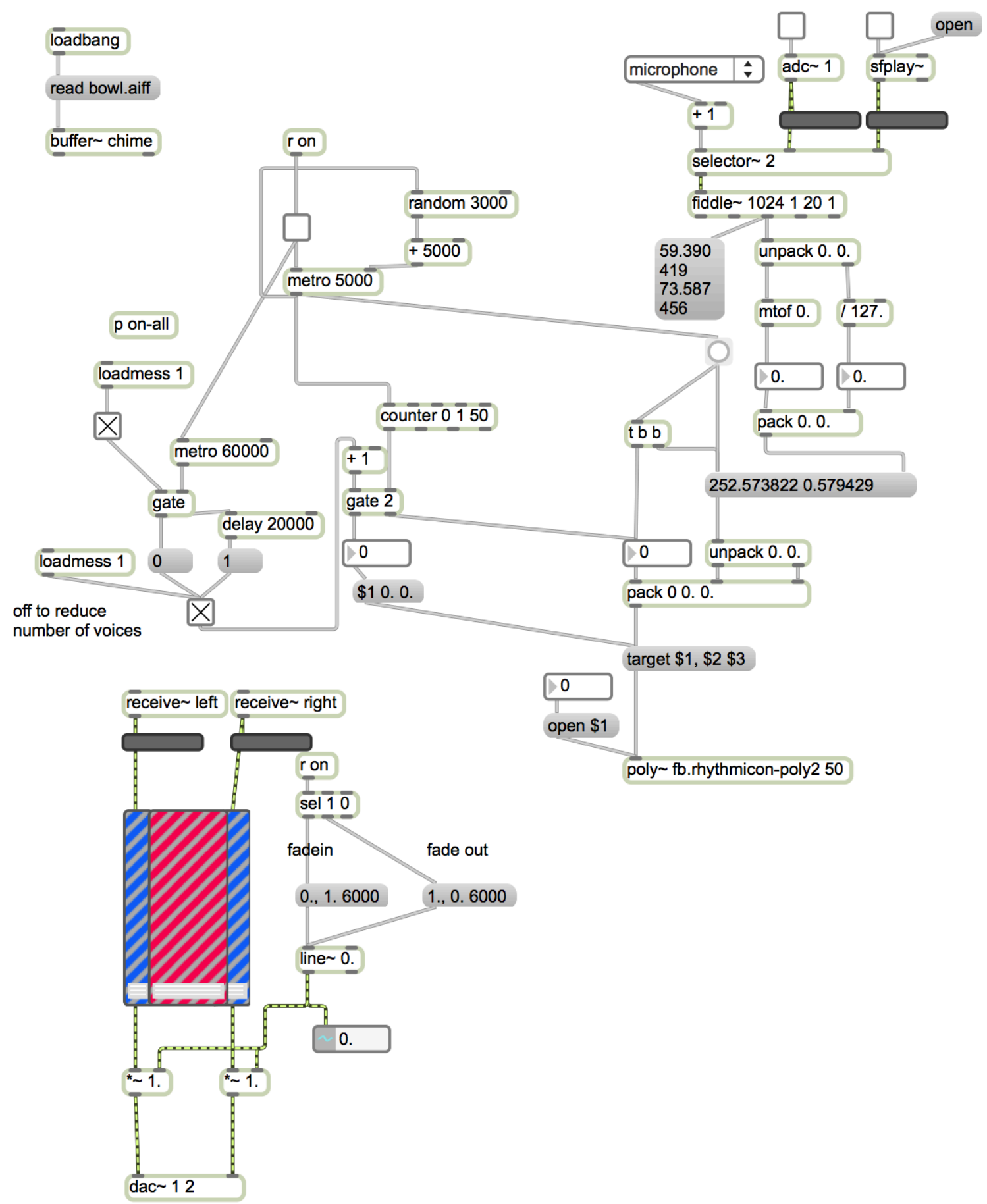




\subsubsection{Rhythmicon - poly $\sim$ subpatch}

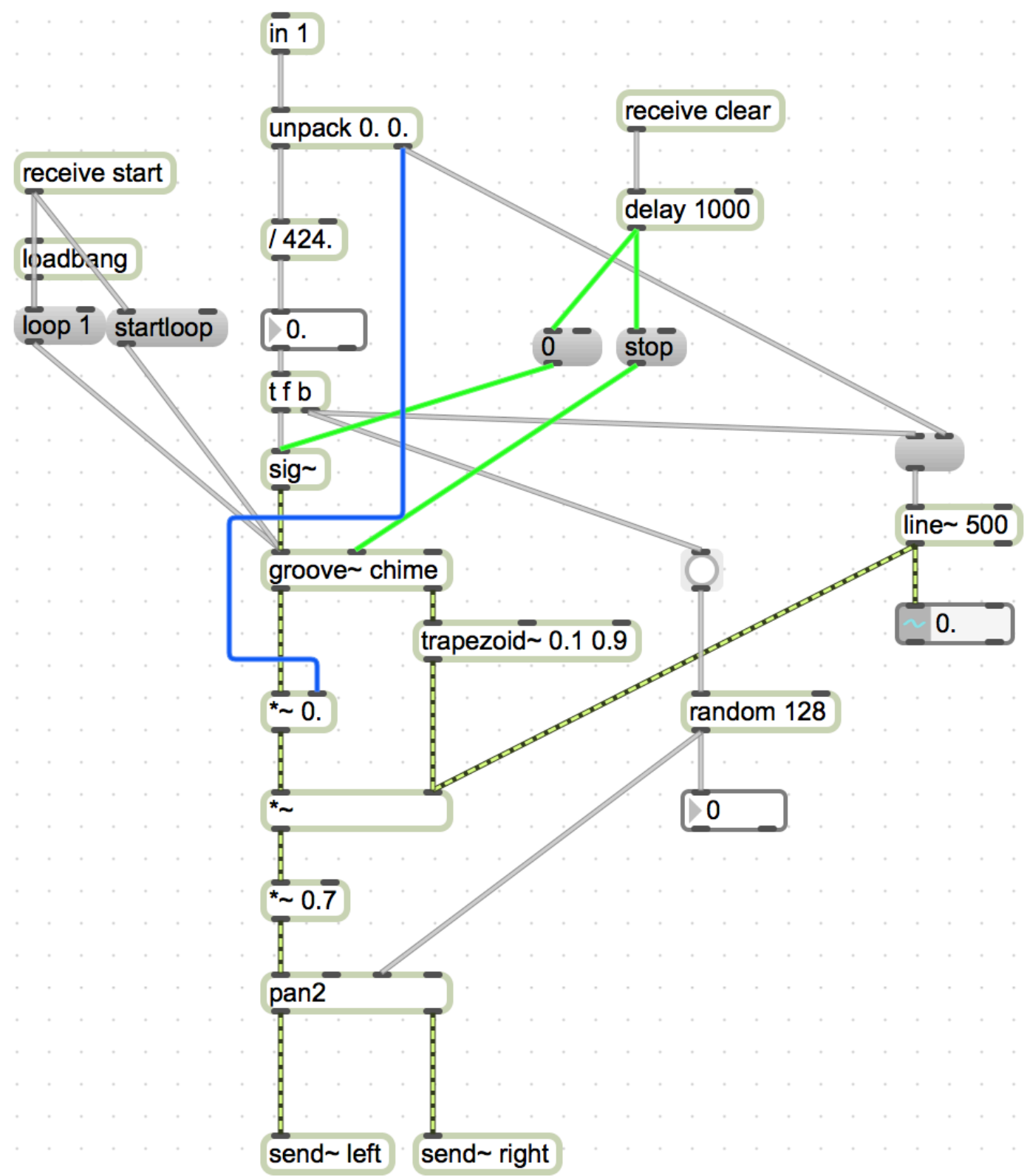


9. APPENDIX 2 - D'IMPROVVISO DA IMMOBILE S'ILLUMINA - SCORE (SEE ADDITIONAL FILE) 